\title{
PROBLEMÁTICA EN TORNO A LA LIMITACIÓN DE LA PRESTACIÓN EN LOS SEGUROS DE RESPONSABILIDAD CIVIL EN ARGENTINA*
}

\author{
LIABILITY INSURANCE POLICIES: \\ LIMITS QUESTIONED IN ARGENTINA
}

\author{
MARÍA FABIANA COMPIANI** \\ CARLOS JOSÉ MARÍA FACAL *** $^{* *}$
}

Fecha de recepción: 9 de julio de 2017

Fecha de aceptación: 24 de agosto de 2017

Disponible en línea: 30 de noviembre de 2017

\section{Para Citar este articulo/To cite this article}

\author{
Compiani, María Fabiana \& Facal, Carlos José María, Problemática en \\ torno a la limitación de la prestación en los seguros de responsabilidad \\ civil en Argentina, 47 Rev.Ibero-Latinoam.Seguros, 15-75 (2017). https:// \\ doi.org/10.11144/Javeriana.ris47.ptla \\ doi:10.11144/Javeriana.ris47.ptla
}

* Artículo de reflexión, desarrollado a partir de la conferencia dictada por los autores en el marco ponencia correlatoría de la sección nacional de Argentina en el XIV Congreso del Comité Iboerolatinoamericano de AIDA - CILA. Santa Cruz de la Sierra - Bolivia. 2 a 5 de mayo de 2017.

** Abogada de la Universidad del Museo Social Argentino. Realizó curso de posgrado de "Seguro contra la Responsabilidad Civil", de la Universidad de Buenos Aires. Doctoranda en Derecho Privado de la Universidad de Ciencias Empresariales y Sociales. Profesora de la Facultad de Derecho y Ciencias Sociales de la Universidad de Buenos Aires. Vicepresidente de la Asociación Argentina de Derecho de Seguros. Contacto: compiani@lacaja.com.ar

*** Abogado de la Facultad de Derecho de la Universidad Nacional de Buenos Aires. Especializado en Derecho de Seguros en la Facultad de Derecho de la misma Universidad. Director y profesor de la Especialización en Seguros. Facultad de Ciencias Económicas y Empresariales. Universidad del Salvador, Buenos Aires, Argentina. Titular del Estudio "Facal, Martin \& Asociados - Abogados", especializado en derecho de seguros, riesgos del trabajo, derecho comercial y del trabajo. Contacto: cfacal@facalmartin.com.ar 


\section{RESUMEN}

El seguro contra la responsabilidad civil nació para proteger el patrimonio de quienes contratan este seguro. Como todo seguro, reconoce límites precisos: el daño causado, la suma asegurada y otras estipulaciones que fijan descubiertos a cargo del propio asegurado y exclusiones de cobertura. Pero al mismo tiempo, el seguro contra la responsabilidad civil contribuyó a la expansión de las indemnizaciones que acuerdan los tribunales. El derecho moderno pretende una reparación creciente de los damnificados y, en su afán de brindar soluciones satisfactorias a las víctimas, empiezan a dictarse algunas sentencias que pretenden desconocer los límites tradicionales y hasta la misma viabilidad del seguro contra la responsabilidad civil. Los autores dejan entrever que quizá haya llegado la hora de recurrir a otras herramientas para dar respuesta a quienes sufren daños.

Palabras clave: Seguro; responsabilidad civil; límites a la cobertura; indemnizaciones; contratos; derecho de terceros. 


\begin{abstract}
Liability insurance was born with the goal of protecting the net worth of the assureds. Like other insurance products, it has clear and pre-stated boundaries: the actual damage, the insured capital, and other stipulations which establishes deductibles and coverage exclusions. On the other hand, Liability insurance has contributed to the expansion of the tort system. Courts, now a day, aim at granting extensive indemnifications to the damaged. While the civil courts aspire to repair losses adequately, some court decisions disregard the traditional limits and the future of Liability insurance. The authors wonder whether it is about time to think in alternative solutions for those who ask for damage compensations.
\end{abstract}

Keywords: Insurance; liability insurance; insurance limits; tort; contracts; third parties' rights.

\title{
SUMARIO
}

INTRODUCCIÓN. 1. PARTICULARIDADES DEL PRINCIPIO INDEMNIZATORIO EN EL SEGURO CONTRA LA RESPONSABILIDAD CIVIL: a) finalidad resarcitoria; b) principio indemnizatorio; c) las particularidades en el seguro contra la responsabilidad civil. 2. DISTINCIÓN ENTRE LAS CLÁUSULAS LIMITATIVAS DE LA RESPONSABILIDAD Y LOS LÍMITES DE LA PRESTACIÓN A CARGO DEL ASEGURADOR (ART. 1121 CC Y CN). 3. FRANQUICIA Y DESCUBIERTO OBLIGATORIO: EXORBITANCIA VERSUS RAZONABILIDAD; a) La franquicia y el descubierto obligatorio; b) La aparición de franquicias y descubiertos exorbitantes; c) La regla de la oponibilidad de la franquicia al damnificado; d) La excepción: la franquicia irrazonable por su desmesurada cuantía. Su sanción; e) El fallo de la Corte en el caso "Ortega" convalida la nulidad de la franquicia convencionalmente establecida en el transporte ferroviario de pasajeros; f) Síntesis. 4. SUMA ASEGURADA: a) La suma asegurada como límite de la obligación del asegurador. Suficiencia. Su cuestionamiento; b) Los intereses y la inflación; c) Las costas también integran la garantía a cargo del asegurador; d) La excepción: proceso mantenido por decisión manifiestamente injustificada del asegurador y la aplicación íntegra de las costas; e) Los intereses y las costas. Regla proporcional. 5. LOS LÍMITES EN EL SEGURO AUTOMOTOR OBLIGATORIO. LA CUESTIÓN EN EL MERCOSUR: a) El SOA en Argentina; b) Mercosur. CONCLUSIONES. 6. BIBLIOGRAFÍA 


\section{INTRODUCCIÓN}

Antes de entrar en la materia cuya exposición nos ha sido confiada, creemos necesario reflexionar sobre la evolución habida en el seguro contra la responsabilidad civil.

Las miradas sobre esta cobertura han cambiado, pero los cambios de mirada no han sido parejos ni compartidos. A consecuencia de esta dispar evolución, algunos seguros ofrecen soluciones insuficientes y muchos asegurados quedan inadecuadamente protegidos.

Pero el cambio de mirada ha traído también aparejado un cambio de protagonismo. Desde hace tiempo, la sociedad, sus juristas y magistrados, ponen el acento en la protección de la víctima y relegan a un segundo plano, subordinado y de menor entidad, la protección del patrimonio del responsable civil, es decir del asegurado.

Hace más de cuarenta y cinco años, el Profesor Doctor Juan Carlos Félix Morandi nos alertaba que "en sus orígenes todos los países estructuraron el seguro de responsabilidad civil sobre el clausulado de las pólizas, en el único interés del asegurado responsable”, prescindiéndose por completo del "tercero damnificado".

El seguro de la responsabilidad civil nació como consecuencia de las leyes europeas del siglo XIX que responsabilizaron a los empleadores por los accidentes del trabajo ${ }^{2}$.

Este seguro, hijo del capitalismo, se desarrolló a su ritmo acelerado. Nuevas empresas y productos, generaban riesgos hasta entonces desconocidos y los empresarios, que arriesgaban su capital, deseaban mantener cubiertas sus espaldas, preservándolo.

1 Morandi, Juan C. F. "Estudios de Derecho de Seguros". $1^{\circ}$ Ed. Pannedille. Buenos Aires, 1971. Capítulo IX, pág. 385.

2 Entre otras la Employers' Liability Law inglesa, de 1880 y la Loi du 9 avril 1898 en Francia. La primera compañía en ofrecerlo fue, precisamente, Employers Liability Assurance Corporation Ltd en Inglaterra, la cual estableció una filial en Boston en 1886. En 1905 comienza a comercializarse otras coberturas, tales como RC industrial (productos), RC contratistas, RC comprensiva, $\mathrm{RC}$ ascensores, RC espectadores de teatros, RC automóviles. En 1920 se ofrece por primera vez RC aviación, RC médicos y cirujanos, RC hospitales, RC profesional y RC directivos y funcionarios. 
Nacía con sumas aseguradas muy bajas y descubiertos relativamente altos, con el objetivo de promover la prevención y estimular la diligencia, pero desconociendo las necesidades de las víctimas. Y como relata Morandi, "el seguro se mantuvo en la clandestinidad frente al tercero", prohibiéndose al asegurado revelar su existencia y citar en garantía al asegurador $^{3}$.

Pero con la invención de este seguro, por otro lado, se produjo lo que el Profesor Doctor Sánchez Calero ha denominado "la interferencia recíproca en el crecimiento de la responsabilidad y del seguro" ${ }^{\text {. Se }}$ refiere que a medida que la sociedad identificaba y reconocía nuevos supuestos de responsabilidad civil, se producía un desarrollo de este seguro, el cual, al dotar de "bolsillos más profundos" y protegidos a los que asumían riesgo, expandía aún más las fronteras de la reparación. Advierte, sin embargo, que como el asegurador sólo puede moverse en el campo de lo previsible, es importante que la responsabilidad civil, aunque cambiante, no abandone ese terreno.

Por otro lado, la generalización de los seguros de responsabilidad civil y su imposición como obligatorios para la realización de ciertas actividades cotidianas - como la conducción de vehículos o la enseñanza en las escuelas- han contribuido a que la responsabilidad civil perdiera el carácter de sanción a quien generó un daño y el favorecimiento de conductas cuidadosas. El foco se centra en la necesidad de que quien haya sufrido un daño, reciba adecuada reparación.

En algunas legislaciones, el seguro de responsabilidad civil ha evolucionado hasta convertirse en un "seguro de accidentes" que ya no cubre el patrimonio del responsable del daño. Son seguros cuya contratación obligatoria la ley impone a los generadores del riesgo (por ejemplo, automovilistas o empleadores). Estas coberturas brindan protección directa a las víctimas, sin exclusiones de cobertura o con exclusiones de cobertura extremadamente limitadas en el texto legal, y confieren acción directa a los damnificados.

3 Morandi, op y loc citados.

4 Sánchez Calero, Fernando, "Seguro de Responsabilidad Civil", en Sánchez Calero, Fernando (Director) Ley de Contrato de Seguro. Comentarios a la Ley 50/1980 de 8 de octubre y a sus modificaciones. Thomson-Aranzadi, $3^{\circ}$ edición, Navarra, 2005. Página 1293. 
Como señala el Prof. Sánchez Calero en la obra citada, el primer paso hacia este tipo de coberturas se dio en los seguros obligatorios de accidentes del trabajo (por ejemplo, en Argentina instrumentado por Ley 24.557 de Ley de Riesgos del Trabajo), donde se abandonó por completo el seguro de responsabilidad civil del empleador: lo relevante será evaluar el daño sufrido y repararlo conforme las pautas indicadas por la ley. Muchos seguros de protección a las víctimas de los accidentes de la circulación apuntan en la misma dirección.

Pero las nuevas concepciones vienen con dolores de parto. Muchas veces las coberturas brindadas por seguros de responsabilidad civil tradicionales son forzadas, en numerosas sentencias judiciales, en el afán de reparar los daños sufridos por las víctimas. Porque es muy frecuente que, ante el crecimiento de las indemnizaciones, que tienen la aspiración de plenitud (art. 1740 CCyCN argentino), la cercanía a ese ideal sólo será alcanzable en la medida que un asegurador afronte el desembolso correspondiente.

La dinámica de ambos institutos, correlacionados pero independientes, está distanciándolos. Mientras, en el seguro contra la responsabilidad civil tradicional, "la obligación que asume el asegurador lo es sólo en favor de asegurado", el derecho civil ha fijado su mirada y objetivo en el resarcimiento de la víctima y sólo mira esta cobertura como el medio para garantizar a la víctima el efectivo cobro de la indemnización que le corresponde.

Pero la tensión entre damnificados, responsables civiles y aseguradores no es la única que acecha al seguro de responsabilidad civil.

Este seguro, que no fue previsto en las legislaciones hasta entrado el siglo $\mathrm{XX}^{6}$, y su regulación nació de los contratos al amparo del principio decimonónico de la autonomía de la voluntad ${ }^{7}$.

5 Stiglitz, Rubén S. y Stiglitz, Gabriel A. Derecho de Seguros. $5^{\circ}$ edición actualizada y ampliada. Buenos Aires, La Ley, 2008. Tomo IV. Capítulo XLIX. Acápite 1317. Página 3.

6 Siendo la ley mexicana de 1935 una de las pioneras.

7 López Saavedra, Domingo M. en Martorell, Eduardo (Director), Tratado de Derecho Comercial (Tomo V-Seguros). Ed. La Ley 2010. Acápite 120, página 270. Y especialmente, referido al seguro de responsabilidad civil en op. y loc. cit. Capítulo 23, acápites 164 y 165 cuando habla de los seguros de rembolso y seguros de responsabilidad civil con base reclamos. Allí defiende este tipo de coberturas, no previstas en la ley argentina, apelando a la libertad contractual. Debe tenerse presente que algunas de estas coberturas, especialmente los seguros con base reclamos, han sido incorporados expresamente en diversas legislaciones, como la española de 1980 y la mexicana en 2002. 
Sin embargo, la legislación rectora de los contratos ha sufrido también una evolución, limitativa de la libertad contractual absoluta, que era la norma en los códigos de dos siglos atrás.

Los seguros contra la responsabilidad civil son contratos que se celebran por adhesión a cláusulas generales predispuestas por el asegurador $-\mathrm{y}$ a veces por el reasegurador- $\mathrm{y}$ en algunas coberturas (responsabilidad civil hechos privados), incluso encuadran entre los seguros de consumo.

Consecuentemente, los contratos deberán ser leídos e interpretados a la luz de las normas que gobiernan los contratos, las que se han tornado más tuitivas de la parte más débil. Así, el código civil y comercial de la Argentina, vigente desde agosto de 2015, permite a los jueces declarar nulas las cláusulas abusivas de los contratos celebrados por adhesión a cláusulas generales predispuestas o de los contratos de consumo e integrar los mismos si no pudieran funcionar sin la cláusula observada.

Bajo esa óptica son varias las voces que se inclinan por considerar abusivas las pólizas de responsabilidad civil de reembolso, ya que podrían comprometer la integridad patrimonial de los asegurados y las cláusulas que limitan la cobertura de las pólizas con base reclamos, sobre todo cuando el nuevo código ha estrechado el término de prescripción de la responsabilidad civil contractual de diez años a tres.

A ello se añade en Argentina, las dificultades creadas por un sistema que, si bien en materia de responsabilidad civil reconoce la indemnización plena de las víctimas, admite a la vez su limitación económica por leyes especiales (Contrato de Seguro, Código Aeronáutico, etc.) y sufre la alteración permanente de los valores económicos por la endémica inflación.

Es entonces bajo las tensiones que exhiben los problemas actuales que acabamos de esbozar, que pasaremos revista a los límites de la prestación en los seguros contra la responsabilidad civil. 


\section{PARTICULARIDADES DEL PRINCIPIO INDEMNIZATORIO EN EL SEGURO CONTRA LA RESPONSABILIDAD CIVIL}

\section{a) Finalidad resarcitoria}

Conforme lo sostiene Stiglitz, el contrato de seguro se enrola entre los instrumentos que desarrollan funciones resarcitorias que tienden a recomponer el empobrecimiento que sufren los sujetos expuestos a riesgos, los que son cada vez más numerosos y complejos en la sociedad moderna ${ }^{8}$.

A su vez, la responsabilidad civil constituye una fuente obligacional por la que el deudor debe reparar el daño que ha causado a otra persona, por medio de una indemnización o compensación económica, como consecuencia de la violación de un deber jurídico preexistente y determinado (responsabilidad contractual) o por la violación de un deber jurídico genérico e indeterminado -no causar daño a otro- (responsabilidad extracontractual). En el régimen jurídico argentino ambas órbitas de la responsabilidad civil han sido unificadas en el nuevo Código Civil y Comercial de la Nación (art. 1716 CCyCN).

A fin de evitar una lesión directa al patrimonio de quien ha provocado el daño, el seguro contra la responsabilidad civil permite a un sujeto trasladar las consecuencias dañosas de un evento económicamente desfavorable a otro que es el asegurador, a cambio del pago de un precio.

En consecuencia, mediante el seguro contra la responsabilidad civil se cubren los daños que el asegurado ocasiona a terceros. En algunos casos se impone la contratación obligatoria de un seguro y en otros resulta facultativa9.

8 Stiglitz, Rubén S., Derecho de seguros, $6^{\text {a }}$ ed. act. y ampl., t. 1, La Ley, Buenos Aires, 2016, nro. 5, p. 6.

9 Donati, Antígono, Trattato del dirittodell'assicurazioniprivate, v. III, Milano 1956, nro. 726, p. 333, ha definido al contrato de seguro de responsabilidad civil como aquel mediante el cual el asegurador se obliga a mantener indemne al asegurado de cuanto éste debe satisfacer a un tercero como consecuencia de la responsabilidad prevista en el contrato y derivada de un hecho ocurrido durante la vigencia de la relación aseguradora. 
La finalidad resarcitoria del contrato de seguro en general se desprende del art. $1^{\circ}$ de la ley de contrato de seguro argentina en cuanto le impone al asegurador: la obligación de "resarcir un daño o cumplir la prestación convenida si ocurre el evento previsto" y, con relación al seguro contra la responsabilidad civil, en su art. 109 en cuanto obliga al asegurador "a mantener indemne al asegurado por cuanto deba a un tercero en razón de la responsabilidad prevista en el contrato”.

Como agudamente señala el Profesor Stiglitz “no corresponde genéricamente asignar naturaleza indemnizatoria a la obligación del asegurador en tanto se entienda por indemnización una sanción resarcitoria motivada por el hecho dañoso atribuido a quien deba reparar. Porque en rigor, el pago realizado por el asegurador no configura el resultado de una ilicitud de fuente contractual o extracontractual de su parte, sino precisamente el cumplimiento mismo del compromiso asumido en el contrato de seguro" 10 .

\section{b) Principio indemnizatorio}

Habiendo caracterizado al contrato de seguro en general, y al seguro contra la responsabilidad civil en particular, como una convención con finalidad resarcitoria, su funcionamiento resulta guiado por el denominado principio indemnizatorio. A consecuencia del cual, el cumplimiento de la prestación por el asegurador no debe traducirse en un beneficio para el asegurado o para el tercero damnificado, colocándolos en una situación más favorable a la que tendrían si el siniestro no se hubiese realizado. Se trata de cumplir el principio fundamental del sistema de reparación de daños, en cuya virtud si bien la compensación debe ser integral, colocando a la víctima en la situación que gozaba mientras el hecho no se había producido, ello no implica que pueda constituirse en fuente de enriquecimiento ${ }^{11}$.

El fundamento del principio indemnizatorio es de orden público: impedir que el asegurado provoque deliberadamente los siniestros con la finalidad de recibir un resarcimiento superior al valor del daño o pro-

10 Stiglitz, Rubén S., ob. cit., t. I, no 24, pág. 26.

11 Halperin, Isaac, Seguro, $3^{\text {a }}$ ed. actual. y ampl. por Barbato, Nicolás H., Depalma, Buenos Aires, NRO. 43, p. 638 . 
curárselo a un tercero, evitando que el seguro estimule especulaciones fraudulentas ${ }^{12}$.

Ahora bien, si bien el daño actúa como tope indemnizatorio, es factible que la reparación a la que se obliga el asegurador sea inferior a la cuantía de aquél. Ello significa que el daño que sufre el asegurado o el tercero opera como límite máximo de la obligación del pago del asegurador, pero no constituye un piso mínimo.

De allí que en los contratos de seguro contra la responsabilidad civil se pacten franquicias o descubiertos obligatorios y, también, se acuerden sumas aseguradas, de manera tal que, con abstracción del daño real, cierto y comprobado que sufran el asegurado o el tercero, el asegurado cargará con la cuantía fijada en la franquicia o descubierto obligatorio y la suma asegurada se constituye en límite máximo insuperable a cargo del asegurador ${ }^{13}$.

\section{c) Particularidades en el seguro contra la responsabilidad civil}

La naturaleza del seguro contra la responsabilidad civil imprime particularidades al señalado principio indemnizatorio. Se trata de un seguro que contrata el eventual responsable del daño causado, es decir del asegurado, en su propio interés, y no en interés del tercero damnificado. Tiene por objeto la protección del patrimonio del asegurado, ya que la causa del contrato es la eliminación del daño que sobreviene a éste por el nacimiento de una deuda de responsabilidad civil, sea ésta contractual o extracontractual, y porque quien se asegura es quien tiene a riesgo su patrimonio amenazado por la posibilidad de una reducción derivada de tener que hacer frente al eventual reclamo de un tercero.

La obligación asumida por el asegurador es autónoma respecto de la que tiene el asegurado con el tercero, que tiene su origen en la relación sustancial de responsabilidad, y es reconocida como concurrente frente al tercero (art. $850 \mathrm{CCyCN}$ ).

12 Stigltz, Rubén S.-Compiani, María F., "El orden público en el contrato de seguro", LA LEY 2015F, 622 .

13 López Saavedra, Domingo M., Ley de Seguros Comentada y Anotada, La Ley, Bs. As., 2007, comentario al art. 61, nro. 174, p. 292. 
La obligación de indemnidad que asume el asegurador es sólo a favor del asegurado y no del tercero damnificado, no pudiendo éste invocar el contrato en su favor (art. $1022 \mathrm{CCyCN}$ ). La Ley de Seguros argentina le otorga un privilegio sobre la suma asegurada en caso de concurso o quiebra del asegurado y, sobre todo, le otorga la posibilidad de solicitar la citación en garantía del asegurador, al proceso que haya entablado contra el responsable del daño y lograr que se le extiendan a aquél los efectos adversos de la eventual sentencia condenatoria dictada contra el asegurado. En efecto, la sentencia de condena dictada contra el asegurado, como reza el art. 118, Ley de Seguros, "hará cosa juzgada respecto del asegurador y será ejecutable contra él en la medida del seguro”.

En otros términos, la obligación a cargo del asegurador, en sentido amplio, comprende el pago del capital, los intereses y las obligaciones accesorias (costas del proceso); sin perjuicio de ello, esa indemnidad no es ilimitada, sino que la misma compromete al asegurador "en la medida del seguro", es decir, de acuerdo a la existencia de franquicia, descubierto obligatorio, suma asegurada y demás limitaciones del contrato (que integran la delimitación del riesgo asegurado) ${ }^{14}$.

Stiglitz-Stiglitz, una vez caracterizado el seguro de responsabilidad civil como un contrato que tiene una finalidad resarcitoria modelada por el principio indemnizatorio, añaden que corresponde "acotar el ámbito de la prestación debida por el asegurador, sobre la base del perjuicio o destrucción del interés por el siniestro (medida del daño) y de la suma asegurada (cobertura asumida)", para concluir finalmente remarcando, "la regla que establece el límite máximo de la prestación del asegurador, en la medida de la suma asegurada, consagrada positivamente por el art. 61, segundo párrafo, de la ley 17.418” y que "en nuestra práctica asegurativa, el seguro contra la responsabilidad civil ha sido precisamente concebido, en general, sobre la base de la limitación emergente de la fijación de la suma asegurada"15.

14 Barbato, Nicolás H., "Exclusiones a la cobertura en el contrato de seguros", ED 136-547.

15 Stiglitz, Ruben S.-Stiglitz, Gabriel A., ob. cit., t. IV, nro. 1675, p. 446. 


\section{DISTINCIÓN ENTRE LAS CLÁUSULAS LIMITATIVAS DE LA RESPONSABILIDAD Y LOS LÍMITES DE LA PRESTACIÓN A CARGO DEL ASEGURADOR (ART. 1121 CCYCN)}

En el plano conceptual, la delimitación del riesgo asegurado se distingue claramente de las cláusulas limitativas de los derechos de los asegurados:

a) La delimitación del riesgo precede al nacimiento de los derechos y obligaciones de las partes. Comprende la individualización y determinación de la base del riesgo asegurado y la fijación de los límites económicos, como franquicias, descubiertos, sumas aseguradas. Hace al objeto del contrato.

b) En cambio, las cláusulas limitativas, tanto las exonerativas (que eliminan totalmente la responsabilidad), como las limitativas propiamente dichas (sólo lo hacen parcialmente), evidencian el propósito de liberar o atenuar la responsabilidad del asegurador y, consecuentemente, del derecho a obtener la indemnidad por el asegurado o el pleno resarcimiento del daño, por el tercero. Se aplica en la etapa de los efectos del contrato.

La sentencia del Tribunal Supremo Español del 11 de setiembre de 2006, del Pleno de la Sala, resolvió que el límite del importe de la indemnización por siniestro en el contrato de seguro de automóviles, establecido en el condicionado general, implica delimitación del riesgo y no exige la aceptación específica del art. 3 de la LCS (la norma citada requiere que las cláusulas limitativas de los derechos de los asegurados, sean destacadas en la póliza y específicamente aceptadas por escrito) ${ }^{16}$.

Esta distinción no es menor. Las cláusulas limitativas de responsabilidad pueden ser declaradas abusivas, en tanto importen un desequilibrio significativo en perjuicio del asegurado consumidor.

En cambio, no correspondería tal declaración por exclusiones de cobertura, que integran el objeto del contrato y, por ende, fueron originadas en la materia negocial entre las partes que contratan.

16 Veiga Copo, Abel B., Tratado del Contrato de Seguro, $2^{\mathrm{a}}$ ed., Civitas-Thomson Reuters, España 2012, p. 369. 
La delimitación del riesgo integra el objeto del contrato y, por tanto, no podría ser considerada como cláusula abusiva, ya que son las partes quienes acuerdan sobre el objeto de la contratación ${ }^{17}$. A modo de ejemplo, no podría considerarse abusiva la cláusula por la que en el seguro automotor se cubre sólo la responsabilidad civil hacia terceros y no el casco del rodado contra todo riesgo ${ }^{18}$.

Lo anterior podría cuestionarse en los seguros contra la responsabilidad civil de contratación obligatoria, cuando el asegurador impone una suma asegurada irrisoria o una franquicia desmesurada, por ejemplo, en seguros de responsabilidad civil de los titulares de establecimientos educativos (art. $1767 \mathrm{CCyCN}$ ).

El nuevo Código Civil y Comercial de la Nación argentina, prevé para los contratos por adhesión que las cláusulas abusivas son las que desnaturalizan las obligaciones del predisponente; importan renuncia o restricción a los derechos del adherente, o amplían derechos del predisponente que resulten de normas supletorias; o por su contenido, redacción o presentación, no sean razonablemente previsibles. Las cláusulas abusivas se tienen por no convenidas. Cuando el juez declara la nulidad parcial del contrato, simultáneamente lo debe integrar, si no puede subsistir sin comprometer su finalidad. La aprobación administrativa de las cláusulas generales no obsta a su control judicial (art. 989).

En el contrato de consumo, el control de las cláusulas abusivas no se limita al contenido contractual, sino también a la incorporación de las cláusulas contractuales. Por esta razón, podrá ser declarada abusiva una cláusula aun cuando el consumidor la hubiera aprobado: "Esta regla se aplica, aunque el contrato de consumo sea de adhesión o no, porque la adhesión (que es un problema de incorporación de la cláusula) es indiferente; lo que importa es que sea de consumo"19.

17 Diez-Picazo y Ponce de León, Luis, (Ponente General) Las condiciones generales de la contratación y cláusulas abusivas, Civitas, Madrid, 1996, p. 41.

18 Vazquez Ferreyra, Roberto A., "El seguro de responsabilidad civil y las cláusulas claims made", LA LEY 2006-E, 8 Derecho Comercial Doctrinas Esenciales Tomo IV, 491. Cita Online: AR/ DOC/2696/2006.

19 ARTíCULO 1118.- Control de incorporación. Las cláusulas incorporadas a un contrato de consumo pueden ser declaradas abusivas aun cuando sean negociadas individualmente o aprobadas expresamente por el consumidor. 
Se define la cláusula abusiva conforme a un criterio general: es abusiva la cláusula que, aun habiendo sido negociada individualmente, tiene por objeto o por efecto provocar un desequilibrio significativo entre los derechos y las obligaciones de las partes, en perjuicio del consumidor (art. 1119).

Sin embargo, con acierto se establece que no pueden ser declaradas abusivas las cláusulas relativas a la relación entre el precio y el bien o el servicio procurado y las que reflejen disposiciones vigentes en tratados internacionales o en normas legales imperativas (art. 1121). Finalmente, se establecen las facultades judiciales sobre cláusulas abusivas ${ }^{20}$.

El antecedente de la limitación en cuestión se encuentra en el artículo 4.2 de la Directiva 93/13 de la CEE en materia de contratos de consumo, el art. 132-I del Código de Consumo francés ${ }^{21}$. El artículo 1262 inciso 2 de la "Propuesta para la modernización del derecho de las Obligaciones y contratos" de España (2009), decide en el mismo sentido.

Lo expuesto significa que ni la franquicia o descubierto obligatorio, ni la suma asegurada, podrán ser consideradas como cláusulas abusivas. Sin embargo, la fijación de tales límites económicos al contrato de seguro podría resultar inconstitucional, si fueren irrazonables, o contrariaran la finalidad económica jurídica del contrato o cuando restrinjan de modo inusual o poco frecuente los derechos de los asegurados o terceros.

La impugnación del contrato de seguro por contener cláusulas abusivas sólo podría ser planteada por el asegurado, que es parte del mismo, y no por el damnificado que no integra la relación contractual. Pero, cuando se trate de un seguro de contratación obligatoria, en razón de que los poderes públicos desean brindar protección a terceros expuestos a riesgos determinados, el planteo de inconstitucionalidad de franqui-

20 ARTÍCULO 1122.- Control judicial. El control judicial de las cláusulas abusivas se rige, sin perjuicio de lo dispuesto en la ley especial, por las siguientes reglas: a) la aprobación administrativa de los contratos o de sus cláusulas no obsta al control; b) las cláusulas abusivas se tienen por no convenidas; c) si el juez declara la nulidad parcial del contrato, simultáneamente lo debe integrar, si no puede subsistir sin comprometer su finalidad; d) cuando se pruebe una situación jurídica abusiva derivada de contratos conexos, el juez debe aplicar lo dispuesto en el artículo 1075.

21 Lorenzetti, Ricardo L., Consumidores, 2ª ed. Act., Rubinzal Culzoni, Santa Fe, 2009, p. 299 y 310. 
cias exageradas o de sumas aseguradas irrisorias, aunque estén fijadas normativamente, podría ser intentado también por los damnificados, a quienes la norma que imponía el seguro, buscó proteger.

La opinión expresada en el párrafo anterior, no es compartida por quienes siguen considerando que el seguro de responsabilidad civil, aunque su contratación sea impuesta obligatoriamente, sólo es un contrato entre un asegurador y un asegurado que busca proteger la indemnidad de su patrimonio. Para esta posición, que podemos denominar clásica o restrictiva, el seguro sólo da garantía en la medida pactada. El damnificado sólo podrá dirigir su acción contra el asegurador y cobrarse hasta la suma asegurada y por lo que su crédito exceda a la misma, simplemente, no hay seguro.

La declaración de inconstitucionalidad de límites y franquicias ha sido decretada, aun de oficio, por los Tribunales argentinos ${ }^{22}$.

Ahora bien, los efectos serán distintos si los Tribunales deciden decretar la nulidad o inconstitucionalidad de la limitación relativa a la franquicia o a la suma asegurada o, por el contrario, deciden que las mismas son inoponibles a las víctimas.

En el primer supuesto, el asegurador terminará dando una garantía mayor a la contratada. La sentencia así dictada lo obligará a iniciar un nuevo juicio contra su asegurado para reclamar el pago de la suma que desembolsó sin causa (art. 1794, $1^{\circ}$ párr. $\left.\mathrm{CCyCN}\right)^{23}$.

En la segunda hipótesis, -declaración de inoponibilidad- el asegurador que pagó a la víctima, sin necesidad de promover un nuevo juicio, podrá solicitar el reembolso a su asegurado, ya que el negocio entre las partes no resultó alterado por la decisión judicial.

22 C.N.Civ., Sala A, "Bossio, Jorge Sebastián c/ Expreso Paraná S.A. y otro s/ daños y perjuicios", del 15/09/05, en La Ley tomo 2006-A, pág. 228, con nota a fallo de. Frick, Pablo D “¿Se consolida la doctrina judicial de la “oponibilidad" de la franquicia?"en La Ley tomo 2006-B, pág. 310; con nota a fallo de Stiglitz,Rubén S. y Compiani, María Fabiana "La viabilidad de la declaración de oficio de la inconstitucionalidad de la franquicia en el seguro de transporte automotor de pasajeros" y en Responsabilidad Civil y Seguros 2006-VI, pág. 57.

23 Art. 1794. Caracterización. Toda persona que sin una causa lícita se enriquezca a expensas de otro, está obligada, en la medida de su beneficio, a resarcir el detrimento patrimonial del empobrecido...". 


\section{FRANQUICIA Y DESCUBIERTO OBLIGATORIO: EXORBITANCIA VS. RAZONABILIDAD}

\section{a) La franquicia y el descubierto obligatorio}

Como ya adelantamos, en el contrato de seguro se aplican diversas técnicas que tienen por efecto una delimitación objetiva de la cobertura, dejando ciertas consecuencias dañosas a cargo del asegurado, no obstante, la vigencia del principio indemnizatorio. En ese caso, el asegurador ya no cubre la totalidad de los perjuicios que puede generar la realización del riesgo. La franquicia constituye un supuesto de "fracción del riesgo no cubierta".

Una de sus finalidades es estimular el compromiso del asegurado con la prevención del siniestro. También apunta a liberar al asegurador de los daños minúsculos o insignificantes, aligerándolo de la indemnización de los que no superen dicha base mínima. En esta orientación, en la producción de siniestros carentes de envergadura, los denominados "pequeños siniestros" identificados por la existencia de daños por un monto inferior a una cifra predeterminada, facilita la gestión empresarial y suprime costos administrativos de mayor cuantía que el siniestro mismo ${ }^{24}$.

Como destaca López Saavedra, a veces, son los propios asegurados quienes buscan la reducción de la prima contratando el seguro con importantes franquicias, merced a su respetable capacidad económica ${ }^{25}$.

Se clasifican en franquicia simple o condicional, cuando libera al asegurador de la cobertura de siniestros cuya entidad económica no supere cierto importe. Si lo supera, el asegurador deberá cubrir todo el daño. Por su parte, la franquicia absoluta o incondicional es aquélla que se fija en un importe o porcentaje determinado que se deduce de la indemnización debida, cualquiera sea su cuantía. Puede neutralizarse mediante el pago de una extra-prima.

El descubierto obligatorio, en cambio, no es factible de ser removido mediante su cobertura asegurativa y es impuesto legalmente. Para Meilij,

24 Stiglitz, Rubén S., Derecho de Seguros, ob. cit., t. III, nro. 11548, pág. 308.

25 López Saavedra, Domingo M., ob. cit., comentario al art. 61, pág. 313. 
el descubierto no integra la noción de riesgo, sino que sólo resulta ser una contribución financiera a cargo del asegurado, quien la soporta pasivamente por la deducción que se efectúa en lo que se le debe, al tiempo de practicarse la liquidación del siniestro. Sigue explicando que esta imposición moraliza al seguro, ya que estimula el cuidado del riesgo y la prevención del siniestro, limitando todo lo posible sus consecuencias dañosas; por ello su rol se advierte principalmente en aquellos riesgos en los cuales la conducta del asegurado ejerce mayor influencia en tales aspectos, como los seguros de robo y los de responsabilidad civil ${ }^{26}$.

\section{b) La aparición de franquicias exorbitantes}

El seguro contra la responsabilidad civil, fue implementado con carácter obligatorio para las "empresas transportadoras" por el art. 10 inc. f) de la ley 12.346 (1937). A su vez, el $1^{\circ}$ de febrero de 1993, mediante decreto 692/92, se aprobó el Reglamento Nacional de Tránsito y Transporte, cuyo art. 67 disponía: "Seguro obligatorio. Todo automotor, acoplado o semiacoplado debe estar cubierto por un seguro de acuerdo a las condiciones que fije la autoridad en materia aseguradora, que cubra eventuales daños causados a terceros, incluidos los transportados".

El 23 de diciembre de 1994 se sancionó la Ley de Tránsito 24.449, cuyo art. 68 reprodujo el art. 67 del derogado decreto 692/92. Con apoyo en la "delegación de facultades legislativas" otorgada por el dec. 692/92, la Superintendencia de Seguros de la Nación mediante la resolución 21.999 del 29 de diciembre de 1992, fijó las condiciones que debía reunir el seguro obligatorio. Al año siguiente, el 22 de enero de 1993, la Superintendencia de Seguros de la Nación dictó la resolución 22.058 por la que se establecen "las condiciones mínimas de cobertura del seguro obligatorio al que deberán conformarse las entidades". Estableció un límite mínimo de $\$ 30.000$ para el caso de muerte o incapacidad total o permanente.

Específicamente, en materia de Seguro contra la responsabilidad civil para el Transporte Automotor de Pasajeros, la Superintendencia de Seguros de la Nación, dictó en 1997 la Resolución 25.429/97, como

26 Meilij, Gustavo Raúl, Franquicia y descubierto obligatorio, RCyS 2012-VII, 207. 
consecuencia de la declaración de emergencia del sector (dec. 260/97). En la cláusula 4 del anexo se preveía, bajo el título "Franquicia o descubierto a cargo del asegurado", que "El asegurado participará en cada acontecimiento cubierto que se tramite por la vía administrativa o judicial con un importe obligatorio a su cargo de pesos cuarenta mil (\$40.000)".

Sus fundamentos fueron el aumento de la siniestralidad, la imposibilidad correlativa de aumento de primas, las pérdidas operativas de magnitud sostenida, la licuación de activos debido a la inflación, la eliminación del Instituto Nacional de Reaseguros, entre otros. Destacó que las finalidades eran la sustentabilidad del sistema y el mayor compromiso de las empresas aseguradas tanto en lo patrimonial como en la reducción de la alta siniestralidad del sector, a cuyo efecto instituyó un sistema de premios y castigos a través de la franquicia y empleo de fórmulas de ajuste de primas.

A tales fundamentos sumó los propios del DNU 260/97, en cuya vigencia expresamente se fundó: los altos índices de siniestralidad alcanzados en el tránsito vehicular, el incremento de las demandas judiciales por resarcimiento de daños provocados por accidentes de tránsito, la crisis del mercado de reaseguro y la falta de liquidez de las empresas aseguradoras del sector del autotransporte público de pasajeros.

En materia de transporte ferroviario de pasajeros, mientras el pliego de bases y condiciones de la privatización de algunos de los ramales más importantes que unen la Ciudad Autónoma de Buenos Aires con el conurbano bonaerense, señalaba la obligación del concesionario de suscribir un seguro contra la responsabilidad civil para atender a las posibles víctimas de los accidentes ferroviarios, éstas contrataron un seguro con franquicia de U\$S 300.000 .

\section{c) La regla de la oponibilidad de la franquicia al damnificado}

Si el responsable del daño ha contratado un seguro contra la responsabilidad civil, el damnificado puede pedir que el asegurador del condenado a resarcir, afronte las indemnizaciones debidas. 
Pero deberá respetar, los límites del seguro, ya que el asegurador no es quien causó el daño, sino quien acordó contractualmente con el ahora responsable, garantizar el pago de lo debido, dentro de los límites acordados.

Aunque el damnificado reviste condición de tercero frente a las partes sustanciales del contrato de seguro de responsabilidad civil, le son oponibles las cláusulas delimitativas del riesgo, como ser, las exclusiones de cobertura, los topes de garantía y las franquicias ${ }^{27}$.

Ello resulta inequívocamente de la previsión contenida en el art. 118, párr. $3^{\circ}$ de la ley de seguros, ya que la sentencia de condena contra el responsable civil será ejecutable contra el asegurador "en la medida del seguro", debiendo ello entenderse como entidad cuantitativa referida a los límites económicos de garantía asegurativa, como así a la delimitación subjetiva y objetiva del riesgo ${ }^{28}$.

Por otra parte, la misma norma (art. 118, párr. $3^{\circ}$ in fine, ley 17.418 -Adla, XXVII-B, 1677-) dispone que el asegurador podrá oponer las defensas nacidas antes del siniestro, como lo son justamente las limitaciones cuantitativas de la cobertura. Como la norma no distingue, esta facultad le asiste, cualquiera haya sido la parte que citara al asegurador, dado que la llamada en garantía de este último al proceso constituye facultad tanto del damnificado (art. 118 , párr. $2^{\circ}$, ley 17.418) como del asegurado (art. 118, párr. $4^{\circ}$, ley 17.418) ${ }^{29}$.

Cierto es que los contratos no pueden ser invocados ni perjudicar a terceros (art. 1021CCyCN), por lo que no pueden ser opuestos a éstos (art. 1022CCyCN). Sin embargo, sabido es que la regla de la relatividad de los efectos del contrato no puede ser entendida en sentido absoluto,

27 CNCiv., Sala H, 21/08/96, "Hamud, B. c. Telefónica de Argentina”, ED, Boletín № 4/1996 de la Secretaría de Jurisprudencia de la Cámara Nacional de Apelaciones en lo Civil, p. 36; CNCiv., sala H, 26/12/96, "Herrera, V. c. Portillo, N.", LA LEY, 1997-C, 994, J. Agrup., caso 11.549; ST Misiones, 13/04/98, “Acosta, F. c. Casola, R.”, LA LEY, 1999-F, 794 (42.234-S); CNCiv., sala K, 10/10/2002, “Chamorro C. c. Soto J.”, LA LEY, 2002-F, 598; RCyS, 2002-1060.

28 CNCiv., Sala I, 03/10/96, “Olea de Barrera, M. c. Alonso, R.”, LA LEY, 1997- F, 970, J. Agrup., caso 12.122 .

29 SC Mendoza, Sala 1ª 14/09/95, "Laspada c. Ojeda”, voto de la doctora Kemelmajer de Carlucci, JA, 1996-III-541. 
pues los contratos tienen cierta virtualidad con relación a los terceros ${ }^{30}$. Los contratos pueden ser invocados por los terceros y ser oponibles a éstos bajo determinadas circunstancias ${ }^{31}$.

La ley de contrato de seguro autoriza al damnificado a invocar el contrato de seguro contra la responsabilidad civil celebrado entre el responsable del daño y el asegurador, citando en garantía a este último. En la hipótesis, el damnificado tiene derecho, en la medida de su interés, a prevalerse del contrato celebrado por otros y hasta el límite de la protección que ese contrato acuerda.

También es la ley de contrato de seguro la que dispone que el contrato de seguro le será oponible al damnificado, ya que limita la extensión de la condena al asegurador "en la medida del seguro" y lo autoriza a oponer en juicio las defensas nacidas antes del siniestro, cualquiera sea la parte que lo haya citado en garantía al proceso.

En el sentido indicado, la Corte Suprema de la Nación Argentina ha considerado que no hay razón legal para limitar los derechos del asegurador prescindiendo de los términos del contrato de seguro, que la ley reconoce como fuente de la obligación y al que se halla sujeto el alcance de su responsabilidad ${ }^{32}$.

Por tanto, le son oponibles al tercero o, si se prefiere, le afectan o se halla enmarcado, por determinadas estipulaciones negociales, aunque haya sido ajeno a la celebración del negocio o, precisamente, por haber sido extraño al mismo ${ }^{33}$.

En materia de franquicia en el autotransporte público de pasajeros, la oponibilidad de la franquicia había sido decidida por el máximo

30 Stiglitz, Rubén S., "Contratos Civiles y Comerciales. Parte General”, t. I, Ed. AbeledoPerrot, Buenos Aires, 1998, $\mathrm{N}^{\circ} 422$, p. 470.

31 Alterini, Atilio A., "Contratos. Civiles-Comerciales-de consumo. Teoría General”, Ed. Abeledo Perrot, Buenos Aires, 1998, No 8, p. 429.

32 CS, 27/12/96, “Tarante, C. c. Eluplast S.R.L.”, LA LEY, 1997-C, 995, J. Agrup., caso 11.557.

33 CNCiv., Sala H, 26/12/96, "Herrera, V. c. Portillo, N.”, LA LEY, 1997-C, 995, J. Agrup., caso 11.556; ST Misiones, 13/04/1998, “Acosta, F. c. Casola, R.”, LA LEY, 1999-F, 794, 42-234-S. 
Tribunal y en forma mayoritaria por nuestra jurisprudencia ${ }^{34}$. Algunos pronunciamientos contradijeron la doctrina que emergía de esos fallos y postularon la inoponibilidad de la franquicia en el seguro automotor obligatorio (art. 68, ley 24.449 -Adla, LV-A, 327-) 35 . Otros, invocando la irracionabilidad de su cuantía, dispusieron la inconstitucionalidad de la franquicia obligatoria en el seguro de transporte público de pasajeros ${ }^{36}$.

La cuestión había motivado tal variedad de posturas y fundamentos en los distintos fallos de la Cámara Civil capitalina que reveló prontamente la necesidad de la auto convocatoria a plenario, la que se pronunció por la inoponibilidad ${ }^{37}$. Por su parte, la Corte Suprema de Justicia de la Nación fiel a su doctrina consideró el fallo plenario arbitrario y ratificó la oponibilidad de la franquicia ${ }^{38}$.

34 CSJN, 02/10/90, JA 1990-IV-953; ídem 29.08.06, "Villarreal c. Fernández", LA LEY, 09/10/2006; SC Buenos Aires, 02/05/89, LA LEY, 1989-E, 129; íd. CNCiv., sala A, 15/09/2005, "Bossio, Jorge c. Expreso Paraná S.A. y otro”, con nota de Frick, Pablo D, “¿Se consolida la doctrina judicial de la oponibilidad de la franquicia?", LA LEY, 2005-F, 228. íd. CNCiv., Sala C, 20/11/2003, "Rodríguez, Lucía L. c. Gamarra, Wilfrido y otros", con nota de Stiglitz, Rubén S., "La franquicia y su oponibilidad a terceros", RCyS, 2004-72.

35 CNCiv., Sala B, 08/10/2004, “A., M. del C. c. Lemo, Roberto E.”, LA LEY, 2005-A, 803. Con anterioridad a éste, un juzgado de primera instancia había considerado que "el hecho de que las cláusulas generales del contrato de seguro de responsabilidad civil hubieren sido aprobadas por la Superintendencia de Seguros de la Nación, no obsta a que la validez de éstas pueda ser objeto de revisión judicial en tanto, la actividad de dicho órgano no es vinculante para el juez. La resolución 25.429 de la Superintendencia de Seguros de la Nación (Adla, LVII-E, 6127) en cuanto establece una franquicia de $\$ 40.000$ es inválida, $y$, por ende, inoponible al tercero damnificado que reclama una indemnización por daños y perjuicios derivados de un accidente de tránsito desde que la citada norma desnaturaliza la obligación de contar con un seguro de responsabilidad civil y excede la potestad reglamentaria que delegara el art. 68 de la ley 24.449 (Juzgado Nacional de 1a Instancia en lo Civil Nro. 31, 13/05/2004, A., A. M. y otras c. G., D. G. y otro, LL 2006-E, 680, con nota de Carlos A. Ghersi).

36 CNCiv., Sala K, 13/03/2006, LA LEY, 2006-C-511 y RCyS, Rev. 6, junio/2006, p. 108. STJ Entre Ríos, sala 2a, RDCO, 2006-A, 289; CNCom., sala A, 04/08/2006, JA del 13.09.06, con nota de Stiglitz, R. S. - Morello, A. M., "La franquicia irrazonable y la distorsión del contrato de seguros. Jurisprudencia de conceptos y de principios". Por su parte, la Suprema Corte de Justicia de Mendoza, Sala Primera, con voto de la Dra. Aída Kemelmajer de Carlucci, sostuvo que, si bien la regla es la oponibilidad de la franquicia, esa regla no es absoluta, resultando inconstitucional la franquicia irrazonable por su elevado monto (SCJ Mendoza, 20/10/06, "Centeno, María Yolanda c/ Russo, Norberto P.”, El Dial Express, del 23/11/06).

37 "En los contratos de seguro de responsabilidad civil de vehículos automotores destinados al transporte público de pasajeros, la franquicia como límite de cobertura -fijada en forma obligatoria por la autoridad de control de la actividad aseguradora conforme la Resolución № 25.429/97- no es oponible al damnificado (sea transportado o no)" (CNCiv., en pleno, 13.12.06, La Ley 2007-A, 168; DJ 27/12/2006, 1244; RCyS 2007-I, 47).

38 CSJN, 7.8.07, DJ 12/09/07, 99; La Ley 14/09/07, 6. El mismo criterio de Cuello fue reiterado por la Corte a posteriori en "Villarreal", "Obarrio" y "Gauna" del 04.03.08. 
A pesar de ello, buena parte de la Cámara Civil mantuvo la aplicación de la solución del Plenario Obarrio, incorporando nuevos fundamentos con apoyo en la reforma de la Ley 26.361 sobre la Ley de Defensa de los Consumidores y Usuarios ${ }^{39}$. Nuevamente el máximo Tribunal tachó por arbitrariedad esos fallos y mantuvo la oponibilidad de la franquicia ${ }^{40}$.

La cuestión tuvo un giro más. cuando, a pesar de la doctrina ya expuesta, la propia Corte Suprema de Justicia de la Nación, ratificó una decisión de la Cámara Comercial de la Capital Federal, que había sancionado con la nulidad la franquicia en el seguro que cubre al transporte ferroviario de pasajeros $^{41}$. A pesar que, en apariencia, la posición de la Corte en esta ocasión luce contradictoria con el fallo Cuello, el Alto Tribunal no modificó la doctrina de éste, y la viene ratificando hasta la actualidad ${ }^{42}$.

La cuestión dista de haber alcanzado solución. Una última resolución de la Superintendencia de Seguros de la Nación que fijó el contenido del seguro obligatorio contra la responsabilidad civil para el autotransporte público de pasajeros en $\$ 120.000$, la declara inoponible a los damnificados ${ }^{43}$.

El derrotero descripto en prieta síntesis, ha mantenido en las sombras el verdadero debate que la cuestión merece y es si en el seguro automotor obligatorio o en el seguro obligatorio para el transporte público de pasajeros, la franquicia es compatible con el propósito de protección de las víctimas de los accidentes del tránsito. Adelantamos nuestra opinión en contrario.

\section{d) La excepción: la franquicia irrazonable por su desmesurada cuantía. Su sanción}

La regla es que las franquicias son oponibles a los damnificados.

39 CNCiv, Sala K, 21.02.08, LL 15.04.08, p. 4. CNCiv., Sala M, 06.04.09, “D’A. J.L.F. c/ Micrómnibus Norte S.A.", LL del 14.05.09, con nota de Sobrino, Waldo.

40 CSJN, 09/12/2009, Martínez de Costa, María Ester c. Vallejos, Hugo Manuel y otros, La Ley Online AR/JUR/65128/2009.

41 La Sala A de la CNComercial, el 04.08.06, en "Barreiro, Jorge A. c/ Transportes Metropolitanos Belgrano Sur S.A.” (24.08.06, el Dial AA3724), declaró abusiva y dispuso la nulidad absoluta y parcial de la franquicia de USS 300.000 fijada en el seguro que cubre a ese ferrocarril.

42 CSJN, 27/12/2012, Valdez, Pedro Nolasco c. Medina, Norberto Ariel y otros s/daños y perjuicios, LLOnline, AR/JUR/72863/2012.

43 Resolución nº 39.927/2017 SSN. 
La excepción a la regla opera si la franquicia tiene una desmesurada cuantía, tanto en la hipótesis en que sea fijada como obligatoria por una resolución de la autoridad de control, como en el caso en que resulte del convenio de asegurador-asegurado. En el primer caso, el art. 28 de la Constitución Nacional garantiza que la razonabilidad debe estar siempre presente en los actos del Estado.

Es verdad que la Justicia tiene la delicada misión de saber mantenerse dentro de la órbita de su jurisdicción, sin menoscabar las funciones que incumben a los otros poderes.

Pero eso no significa que el Poder Judicial pueda abdicar de ejercer el control de razonabilidad. Lo contrario sería dejar de lado garantías que hacen a la esencia de nuestro sistema republicano de gobierno, cuya integridad pretende resguardarse por medio, entre otros, de la vigencia efectiva de dichas garantías ${ }^{44}$.

La fijación de una franquicia de monto desmesurado de acuerdo a la finalidad económica jurídica del contrato (por ej. cláusula cuarta de la resolución 25.429 para el seguro del autotransporte público de pasajeros) evidencia un ejercicio carente de razonabilidad de las facultades de la Superintendencia de Seguros de la Nación (art. 67, inc. b), ley 20.091 -Adla, XXXIII-A, 150-), en violación a los arts. 17 y 18 de la Carta Magna, en tanto ignoran el derecho del asegurado a la contratación de un seguro que lo ampare contra la mayor exposición patrimonial ${ }^{45}$.

44 En este sentido, se ha pronunciado nuestro más Alto Tribunal, al sostener que "La restricción que impone el Estado al ejercicio normal de los derechos patrimoniales debe ser razonable, limitada en el tiempo, un remedio y no una mutación en la sustancia o esencia del derecho adquirido por sentencia o contrato, y está sometida al control jurisdiccional de constitucionalidad” (CS, Fallos 243:467; 323:1566). Así como que "...cuando un precepto frustra o desvirtúa los propósitos de la ley en que se encuentra inserto, de modo tal que llegue a ponerse en colisión con enunciados de jerarquía constitucional o su aplicación torne ilusorios derechos por ellos consagrados, le es licito al juzgador apartarse de tal precepto y dejarlo de aplicar a fin de asegurar la primacía de la Ley Fundamental, como medio de afianzar la justicia que está encargado de administrar. Esa atribución moderadora constituye uno de los fines supremos del Poder Judicial y una de las mayores garantías con que se ha entendido asegurar los derechos contra los abusos posibles de los poderes públicos” (CS, Fallos 308:857; 311:1937).

45 La Corte ha señalado que "Queda claro, pues, que no es el Poder Judicial quien está facultado para delinear el derrotero de la legislación. Tampoco es el responsable de las consecuencias del error, exceso o irrazonabilidad en que puedan incurrir los poderes a quienes sí les incumbe tal tarea. Pero no puede permanecer inmutable ni convalidar tales desaciertos, so pena de transgredir el mandato constitucional que le ha sido conferido" (CS, 05/03/2003, considerando 55, Supl. Esp. LA LEY, 06/03/2003, p. 22; cc. consider. 23 y 24 , p. 16; consid. 40 y 41, p. 19). 
En este sentido, Stiglitz agrega que en esos casos los jueces deberán revisar el contrato, lo que les permitirá moderar el "quantum" hasta un porcentaje razonable del monto indemnizatorio que, en su totalidad será oponible al tercero damnificado ${ }^{46}$.

Si bien su magnitud puede ser acordada por las partes en consideración a la prima que pueda pagar el asegurado, excepcionalmente, la puede fijar la Superintendencia de Seguros ${ }^{47}$. La desmesura en la cuantificación de la franquicia acaece tanto cuando se la desnaturaliza, como cuando, indirectamente, se afectan los derechos de los damnificados o terceros, para quienes el seguro contra la responsabilidad civil cumple una función de garantía en la efectiva percepción de la indemnización del daño ${ }^{48}$.

En la hipótesis, al fijarse en un monto exorbitante, quedan fuera de la cobertura del asegurador la gran mayoría de los daños, a cargo del asegurado.

Se afectan los derechos económicos de los asegurados, porque el descubierto de esos daños implica, en los hechos, la inasegurabilidad de los acontecimientos dañosos más asiduamente producidos, con la consecuente carga económica para estas empresas que se ven en la imposibilidad de efectuar la adecuada previsión de esos daños través de la técnica de su aseguramiento ${ }^{49}$.

La Cámara Civil de la Capital Federal optó por una solución diversa a las anteriormente planteadas. Dispuso en fallo plenario la inoponibilidad de la franquicia a los terceros, sean transportados o $\mathrm{no}^{50}$.

46 Ver reportaje en LA LEY Actualidad, 21/09/2006.

47 Stiglitz proporciona un ejemplo de fijación por la autoridad de control de una franquicia de cuantía razonable: la que autorizaba a operar en el riesgo del seguro contra la responsabilidad civil de los médicos, que estableció una franquicia equivalente al $10 \%$ de las indemnizaciones con un máximo del 3\% de la suma asegurada y un mínimo del 0,5\%. "Estos porcentajes constituyen una franquicia razonable en su cuantía", Sitglitz, Rubén S., reportaje cit., nota anterior. Esta solución es la que adoptó la Sala A de la Cámara Comercial en el precedente Barreiro (24.08.06, el Dial AA3724),

48 Ver voto de la doctora Míguez como vocal preopinante en el fallo de la sala A de la Excma. Cámara Nacional de Apelaciones de la Capital (24.08.06, el Dial AA3724).

49 Esto es lo sucedido con las franquicias en los seguros para empresas de autotransporte público de pasajeros: fue fijada por la SSN en la suma de $\$ 40.000$. El Presidente de la Cámara Empresaria de Autotransporte de Pasajeros (CEAP), Daniel Millaci, le informaba al Diario La Nación que "el 95\% de los siniestros que suceden lo pagan las empresas de transportes, no la aseguradora" (Diario La Nación, Suplemento Economía, domingo 6 de noviembre de 2005, bajo el título "Cuestionan el seguro del transporte").

50 CNCiv., en pleno, 13.12.06, La Ley 2007-A, 168; DJ 27/12/2006, 1244; RCyS 2007-I, 47. 
Para resolver así, colocó el eje de la interpretación en el criterio solidarista: "El derecho de daños, en su concepción actual, protege al débil y por ende a la víctima; en esa dirección destaca la función social del seguro, como instituto adecuado a la idea solidarista... ". Destacó que "esta franquicia o descubierto a cargo del asegurado desvirtúa lisa y llanamente la obligatoriedad del seguro de responsabilidad que exige la ley 24.449”. Señaló que su cuantía "es irrazonable porque...la gran mayoría de los daños a pasajeros o a terceros no transportados, quedan a cargo de las empresas de transporte debido a que el monto de su resarcimiento no alcanza a superar dicho descubierto", agravando el pasivo de estas empresas y derivando ello en que gran cantidad de víctimas ve imposibilitado el cobro de su indemnización.

Agregó que "La función del contrato de seguro queda desnaturalizada, no sólo porque no se contemplan los derechos del asegurado, en procura de su indemnidad, sino que primordialmente se ven afectados los intereses de los damnificados por accidentes de tránsito, desvaneciéndose la garantía de una efectiva percepción de la indemnización por daños, constituyendo una violación implícita de la finalidad económico jurídica de tal contratación".

Destacó que esa franquicia era incompatible con las otras resoluciones de la SSN que fijaban las condiciones mínimas del seguro automotor obligatorio. Cerró su argumentación dejando a salvo el principio general de la oponibilidad de la franquicia al damnificado ${ }^{51}$.

Por su parte, la Corte consideró arbitrario el fallo plenario de la Cámara Capitalina.

Las principales críticas que mereció el fallo de la Corte en el precedente "Cuello" fueron dirigidas a que el Tribunal no tuvo en cuenta que resolución 25.429/97 se fundó en un decreto de necesidad y urgencia (260/97) que había sido declarado inconstitucional por el mismo Tribunal ${ }^{52}$ : una norma de emergencia debe tener como finalidad proteger los intereses generales de la sociedad y no de determinados individuos, lo que no se cumplía en ese caso. Sobre ella, Alterini había advertido que

51 Para un análisis de los argumentos de la disidencia ver Sánchez, Diego C., "Franquicias y descubiertos", en la obra colectiva patrocinada por la Academia Judicial Internacional, Dupuis, Juan Carlos (Coord.), Seguros I, La Ley, Bs. As., 2008, pág. 109.

52 CSJN, 02.08.00, "Risolía de Ocampo c/ Rojas", LL 2000-D, 593. 
se pretendía llevar alivio al sector del transporte público de pasajeros, mediante el procedimiento de trasladar a la víctima la carga de financiar una crisis a la que es ajena. Tal pretensión, sostiene, lesiona la garantía constitucional de igualdad (art. 16) ${ }^{53}$.

Se añadió que la franquicia fijada en la resolución 25.429/97 es inconstitucional al legislar sobre materias que están reservadas al Poder Legislativo (arts. 75, inc. 12, 76, párr. 1ero. y 99, inc. 2do. C.N.). Se trata de una delegación legislativa prohibida ${ }^{54}$.

No cumple la finalidad de prevención, ni la de la atención de pequeños siniestros, desnaturaliza los fines del seguro tanto con relación al asegurado - prohibiéndole contratar cobertura para el descubierto- ${ }^{55}$, como respecto a la víctima, haciendo cargar sobre esta última la crisis del sector transportista ${ }^{56}$.

La franquicia no favorece a la víctima, sino al asegurador y al asegurado $^{57}$, a la sazón los mismos sujetos, ya que las empresas de seguros del sector, de ramo exclusivo, se encuentran integradas por los propios auto transportistas.

La franquicia es incompatible con la finalidad del seguro obligatorio, desnaturalizándolo. Constituye un apartamiento del derecho positivo y de la finalidad típica del negocio. Los objetivos al establecer la franquicia fueron los de disminuir los costos del seguro y procurar un efecto moralizador al elevar el compromiso del asegurado para evitar la elevada siniestralidad existente. Este último objetivo evidentemente no se ha logrado. El poder administrador equivocó el camino procurando una solución a corto plazo, y si la misma fue de emergencia, tiene desde hace mucho los

53 Alterini, Atilio A., "Moratoria para los autotransportistas", LL 1997-B, 1295 y "Limitación de la responsabilidad ¿sólo para los autotransportistas?, LL 1997-E, 1333.

54 Bidart Campos, Germán, Manual de la Constitución reformada, t. 3, Ed. Ediar, Bs. As., 2001, nros. 26, pág. 21.

55 Stiglitz, Rubén S., "La franquicia en el autotransporte público de pasajeros en el pensamiento de la Corte", JA del 17 de octubre de 2007.

56 SCJMendoza, Sala Primera, 20.10.06, voto de la Dra. Kemelmajer de Carlucci, causa $\mathrm{n}^{\circ}$ 86.383, "Centeno, María Yolanda c/ Russo, Norberto", con comentario de Compiani, M. Fabiana, "La irrazonabilidad de la cuantía de la franquicia", LL del 12 de diciembre de 2006, pág. 1.

57 Tolosa, Pamela, "El seguro obligatorio y la franquicia en un contexto de insolvencia: ¿nuevas soluciones en la ley de defensa del consumidor?, RCyS, 2010-II, 139. 
tiempos agotados. La responsabilidad del Estado en el entuerto existe y podría razonablemente reclamarse. Imponiendo franquicias desmedidas se defraudarán víctimas y se desplomarán los valiosos logros del derecho de daños. La dignidad de seres humanos está en juego ${ }^{58}$.

Por otra parte, el principio de la autonomía de la voluntad no es absoluto, reconoce en la actualidad múltiples limitaciones derivadas del orden público de protección. En definitiva, el Derecho no debe subordinarse a la Economía ${ }^{59}$.

A pesar de las críticas, la Corte mantuvo su criterio hasta la actualidad $^{60}$.

Algunos tribunales decidieron estar a la decisión estable de la Corte, más allá de cual fuere su criterio particular ${ }^{61}$. Otros, en cambio, con

58 Gregorini Clusellas, Eduardo L., "La obligación de seguridad hacia el pasajero y la franquicia del seguro", LL 2006-LA LEY 11/12/2006, 1.

59 En este sentido, las conclusiones de las XXI Jornadas Nacionales de Derecho Civil, celebradas en Lomas de Zamora (www.jornadascivil.com.ar), concluyeron de lege lata: la franquicia es oponible al tercero damnificado ajeno al contrato de seguro, salvo en los casos en que exista obligación legal de contratar un seguro de responsabilidad civil (nro. 2); cuando existe una imposición legal de contratar un seguro de responsabilidad civil, la existencia de una franquicia, como la dispuesta por la Res. 25.429/97, desnaturaliza la esencia del contrato de seguro (nro. 3); la franquicia cuando desnaturaliza la esencia del contrato de seguro resulta una cláusula nula o inoponible a los damnificados (nro. 4); la franquicia regulada por la Res. 25.429/97 es inconstitucional (nro. 6). De legeferenda: debe reafirmarse en el régimen asegurativo argentino la función social del seguro de responsabilidad civil (nro. 1); debe modificarse el sistema argentino de seguro de responsabilidad civil en transporte de pasajeros (nro. 2); debe complementarse el sistema de seguro obligatorio con fondos de garantía. El fondo de garantía tendrá por objeto cubrir la insolvencia del dañador, la falta de cobertura o el anonimato del causante del daño (nro. 3).

60 "Debe dejarse sin efecto, por arbitraria, la sentencia que incluyó en la condena por daños y perjuicios a la aseguradora citada en garantía, por considerar inoponible al damnificado la franquicia acordada entre aquélla y el tomador del seguro, pues, al decidir de ese modo, el a quo prescindió de lo dispuesto por el art. 118 tercera parte de la ley 17.418 (Adla, XXVII-B, 1677) en cuanto establece que la sentencia de condena contra el responsable civil será ejecutable contra el asegurador "en la medida del seguro" y, se apartó de la Resolución 25.429/97 de la Superintendencia de Seguros de la Nación (Adla, LVII-E, 6127) que prevé como cobertura básica del seguro de responsabilidad civil de vehículos destinados al transporte público de pasajeros una franquicia de \$40.000" (De la sentencia de la Corte según la doctrina sentada en "Villarreal" 29/08/2006, LA LEY 2006-F, 3-, a la cual remite, CSJN, 27/12/2012, Valdez, Pedro Nolazco c. Medina, Norberto Ariel y otros s/daños y perjuicios, LLOnline, AR/JUR/72863/2012).

61 "Razones de orden, seguridad, paz y justicia, aconsejan no apartarse de una jurisprudencia que se estima estable, por lo que no resulta procedente otra solución que adherirse al criterio de la oponibilidad de la franquicia. Ello así en razón que la Corte Federal ha ratificado su posición en pronunciamientos posteriores, incluso en su actual composición, sin distinguir según el monto de la franquicia sea irrazonablemente alto o no" (SCJMendoza, 25.06.07 in re "Protección Mutual", 27.07.07 in re "Steiner", 28.08.07, "Rutiman"). "Aunque el sistema argentino no se rige por la regla del stare decisis vertical, razones de buen orden y de seguridad jurídica aconsejan que los tribunales inferiores acomoden su jurisprudencia a la de la Corte Federal. Creo que no cabe otra solución que 
nuevos fundamentos, mantuvieron su criterio opuesto. ${ }^{62} \mathrm{Sin}$ embargo, la Corte también desechó los nuevos fundamentos provistos por la reforma a la ley de defensa de los consumidores y usuarios (Ley 24.240 reformada por la Ley 26.361) ${ }^{63}$.

También la mayoría del tribunal civil capitalino mantuvo su rebeldía, lo que hiere gravemente la celeridad y economía del proceso, haciendo necesario el pronunciamiento del máximo Tribunal en todos los casos que llegan a su conocimiento. Sin embargo, ello también revela que se percibe la injusticia de consagrar una franquicia en un seguro automotor obligatorio cuyo norte no es otro que el de la protección de las víctimas de los accidentes de tránsito ${ }^{64}$.

adherirse al criterio de la oponibilidad de la franquicia" (C2da.ACC, Minas, de Paz y Tributario de la 1era. Circ.Jud. Mendoza, 13.06.08, "Nievas c/ Guirin”, exp. n 55.286/33.278). Ídem, SCBs. As. 23.04.08, causa C. 94.988, "Romeggio Belkis, Amanda contra Alí, Claudio y otros/ Daños y perjuicios"; id. 17.08.11, "Díaz, Alicia S. c/ Moreno, Carlos s/ Daños y perjuicios”, La Ley Online, AR/JUR/43854/2011.

62 "Corresponde apartarse de los fallos de la CSJN aportando nuevos argumentos que permitan prescindir de la doctrina jurisprudencial de ese Tribunal aplicable al caso. Sin duda, el derecho a la salud y a la integridad física, garantías constitucionales de carácter inalienable, predominan por su jerarquía, sobre los fines que han determinado la sanción de la mencionada resolución. El imperativo de justicia en la reparación no debe seguirse sólo en apariencia. Se entiende por razonable lo que resulta conforme a la razón; lo justo, moderado y prudente, con arreglo a lo que dice el sentido común. El elevado monto de la franquicia establecido en la reglamentación dictada por la Superintendencia no cumple con el recaudo de razonabilidad. La víctima no elige con quien sufrir el daño: la resolución viola el principio de igualdad" (CNCiv, Sala K, 21.02.08, LL 15.04.08, p. 4). "No obstante que, como sostiene la recurrente, la CSJN se ha pronunciado en varias oportunidades a favor de la oponibilidad de la franquicia, después se produjo la modificación de la LDC en varios aspectos que establecen una solución acorde con la consagrada en el fallo plenario, aspecto respecto del cual no ha mediado pronunciamiento alguno de la Excma. Corte. Resulta totalmente inaplicable a las relaciones de consumo el concepto de efectos relativos de los contratos (arts. 1995 y 199 del C. Civil), con relación a personas que están expuestas a dichas relaciones de consumo. Existiendo una modificación legal relevante y nuevos argumentos que no han sido tenidos en cuenta por el alto tribunal en su momento, las invocadas decisiones de la Corte no constituyen óbice para continuar aplicando el fallo plenario "Obarrio” (CNCiv., Sala M, 06.04.09, “D’A. J.L.F. c/ Micrómnibus Norte S.A.”, LL del 14.05.09, con nota de Sobrino, Waldo).

63 "Resultan ineficaces los argumentos de la actora referentes a la aplicación al caso de la ley de Defensa del Consumidor, según la modificación de la ley 26.361, para modificar el criterio de la Corte Suprema respecto al alcance de la franquicia estipulada en el contrato de seguro de transporte público de pasajeros" (CSJN, 09/12/2009, Martínez de Costa, María Ester c. Vallejos, Hugo Manuel y otros, La Ley Online; AR/JUR/65128/2009. El voto en disidencia de la Dra. Argibay declaró inadmisible el recurso por aplicación del art. 280 del Cód. Procesal). "La condena en la acción de daños no podrá ser ejecutada contra la aseguradora sino en los límites de la contratación, dado que la franquicia prevista en el contrato de seguro es oponible al tercero damnificado y los argumentos del a quo referentes a la aplicación al caso de la Ley de Defensa del Consumidor, según la modificación de la ley 26.361, son insuficientes para modificar ese criterio (CSJN, 21/02/2013, Calderón, Andrea Fabiana y otros c. Marchesi, Luis Esteban y otros, LL 06/03/2013, 11, DJ 10/04/2013, 30, AR/JUR/277/2013.

64 Debe hacerse extensiva la condena a la aseguradora citada en garantía, pues, la cláusula contractual por la que se estipula la franquicia que intenta hacer valer resulta nula, pues, es evidente 


\section{e) E1 fallo de la Corte en el caso "Ortega" convalida la nulidad de la franquicia convencionalmente establecida en el transporte ferroviario de pasajeros}

En sentido inverso a su doctrina con relación a la franquicia del autotransporte público de pasajeros, la Corte dispuso desestimar la queja interpuesta contra la sentencia que declaró la nulidad absoluta de la cláusula que limitaba la responsabilidad de la aseguradora en la medida de la franquicia del seguro, en el seguro que cubre el transporte ferroviario de pasajeros. Esa franquicia había sido fijada en el contrato de seguro contra la responsabilidad civil, suscripto por la concesionaria del servicio público con una aseguradora nacional, en el orden de los U\$S 300.000. El Tribunal destacó que, en el pliego de bases y condiciones de la concesión, el Estado Nacional había exigido la contratación de un seguro contra la responsabilidad civil que amparara a las víctimas de los accidentes ocasionados por el Ferrocarril, lo que evidentemente no podía considerarse cumplido con lo contratado, ya que la exorbitante franquicia había determinado que, en escasísimas oportunidades, el

su incompatibilidad con los principios esenciales de buena fe y razonabilidad porque obsta a la obtención de la finalidad práctica principal que deriva de la naturaleza del contrato contra la responsabilidad civil (CCiv, sala H, Martínez, Osvaldo Lino c. Línea de Transporte 117 Dota S.A. s/daños y perjuicios, 04/10/2012, La Ley Online, AR/JUR/59075/2012). La franquicia que limita la cobertura de la aseguradora es inoponible a la víctima de un accidente de tránsito, si existe una imposición legal de contratar un seguro de responsabilidad civil, pues ello desnaturaliza la función tuitiva de la víctima, y la esencia del contrato (ídem sala C, Pecorelli, Omar Hugo c. Nogues, Fabio Gustavo y otro, 06/09/2012, La Ley Online AR/JUR/62253/2012). "Es inoponible al damnificado la franquicia establecida en el contrato de seguro pues, conforme lo dispuesto por el artículo 303 del Código Procesal Civil y Comercial de la Nación, debe aplicarse la doctrina plenaria sentada en la causa “Obarrio" - 04/03/2008, LA LEY 27/03/2008, 3 -, sin perjuicio de lo dictaminado por la Corte Suprema de Justicia de la Nación en sentido contrario, ya que la obligatoriedad de sus fallos no se extiende más allá de las causas para los cuales han sido dictados (ídem sala B, Martínez Astudillo, Silvia c. U.T.E. Futuro y otros s/ daños y perjuicios, 13/04/2012, RCyS 2012-VII , 232). En contra, la Sala G del mismo Tribunal ha considerado que "La franquicia contenida en la póliza del seguro de transporte público de pasajeros es oponible a la víctima, pues la doctrina plenaria del caso "Obarrio" -2008/03/04, La Ley 2008/03/27-, que establece lo contrario, fue descalificada por la Corte Suprema de Justicia de la Nación por arbitrariedad normativa, por lo que carece de la fuerza obligatoria del art. 303 del Cód. Proc. Civil y Comercial (CCiv., sala G, 25/09/2012, Kissner, Sara y otros c. Donadío, Pedro Marcelo y otros s/daños y perjuicios, La Ley Online AR/JUR/52714/2012). Ídem sala E, Tamburro, Ana Luisa c. Seubart, Rodolfo y otros s/daños y perjuicios, 14/03/2013, La Ley Online AR/JUR/6179/2013). La situación de la jurisprudencia del Tribunal capitalino se complica aún más a partir que la ley 26.853 derogó el art. 303 del Cód. Procesal Civil y Comercial que establecía la obligatoriedad de los plenarios. Sin embargo, la CSJN mediante Acordada 23 del 14.08.13 dispuso: "Declarar que la operatividad de los recursos procesales que contempla la ley 26.853 se halla supeditada a la instalación y funcionamiento de las cámaras federales y nacionales que crea. Hacer saber que oportunamente el Tribunal dictará las medidas conducentes para llevar a cabo la puesta en funcionamiento, instalación y habilitación de los nuevos tribunales que trata la presente”. 
asegurador tuviera que enjugar los daños ocasionados por la asegurada a sus pasajeros ${ }^{65}$.

La Corte Suprema de Justicia sostuvo que no se observaba que la decisión del a quo carezca de fundamentación o prescinda de la solución normativa prevista para el caso, pues, aun cuando la ley considera que la oponibilidad de la franquicia es la regla -art. 109 de la ley 17.418-, ello no impide discriminar entre la diversidad de situaciones que pudieran plantearse y reconocer que cuando se ha estipulado una franquicia se afecta el acceso a la reparación de los daños sufridos por la víctima del accidente, principio de raíz constitucional por cuya tutela corresponde velar a los magistrados.

Para salvar la contradicción evidente con el precedente "Cuello" y los que le sucedieron, precisó que en materia de servicio público ferroviario no existe una expresa obligación legal que imponga a los concesionarios y a las aseguradoras establecer una franquicia en los contratos de seguro de responsabilidad civil que celebren.

Agregó que tales franquicias relacionadas con el transporte público automotor no eran susceptibles de los juicios de reproche formulados para el caso del seguro del transporte ferroviario, ya que "no aparejaban la desnaturalización del seguro contratado, además de que no contrariaban disposiciones relativas al orden público que pudiesen privarlas de validez a la luz de las reglas jurídicas aplicables " ${ }^{\prime 6}$.

En definitiva, al Corte hizo suyo el dictamen del Procurador General de la Nación ${ }^{67}$.

65 El tribunal expresó que "al celebrar el contrato de seguro de responsabilidad civil, ni el asegurador ni el asegurado debieron apartarse de los términos del Pliego de Bases y Condiciones Generales como así tampoco de lo estipulado en el Contrato de Concesión de Servicios Ferroviarios de Pasajeros correspondiente al Grupo de Servicios 7, suscripto el 24 de noviembre de 1999 entre el entonces Ministerio de Economía y Obras y Servicios Públicos y el concesionario demandado. Destacó que, de dicho marco normativo, de índole convencional, resultaba inequívoca la relevancia que el concedente le otorgó a la obligación del concesionario, en el marco de un contrato administrativo, de tomar a su cargo un seguro contra la responsabilidad civil frente a terceros".

66 CSJN, 20/10/2009, “Ortega, Diego Nicolás c. Transporte Metropolitano General Roca S.A.”, RCyS 2009-XI, 112, LL 12/11/2009, 6 - DJ 30/12/2009, 3707.

67 El dictamen del Procurador valoró que la franquicia absoluta acordada por la suma de U\$S 300.000 por "ocurrencia", conforme a las condiciones particulares de la póliza contratada, "resulta irrazonable, en tanto produce un quebrantamiento de la obligación esencial de mantener indemne al asegurado, lo 
También la doctrina que emerge de este fallo de la Corte Nacional es mantenida por el Tribunal hasta la actualidad ${ }^{68}$.

\section{f) Sintesis}

En el contrato de seguro contra la responsabilidad civil, la franquicia como límite económico de la cobertura asegurativa es, en principio, oponible al damnificado.

Sin embargo, la aparición del fenómeno de las franquicias excesivas y, en ocasiones, exorbitantes, ha creado la necesidad de admitir la excepción al principio general de su oponibilidad. La sanción que corresponde en los casos de franquicias desmesuradas será la de la inconstitucionalidad de la resolución de la autoridad de control que la fije o la nulidad parcial y absoluta de la cláusula convencionalmente incorporada en la medida de su exceso.

En materia de seguro automotor obligatorio el art. 68 de la Ley de Tránsito no prevé la existencia de franquicias y si bien delega-indebida-

que llevaba a un estado de desprotección de la casi totalidad de los terceros damnificados. La empresa asegurada no pudo ni debió desconocer que casi la totalidad de los riesgos de mayor probabilidad de siniestro en materia de transporte ferroviario no superan el importe de la franquicia pactada. Tampoco pudo pasar inadvertida para la aseguradora la situación de ese sector del transporte público de pasajeros, el estado de emergencia de las empresas prestadoras del servicio, la alta siniestralidad, el incremento de las colisiones con vehículos, ciclomotores y peatones, la alta actividad litigiosa, ni tampoco el monto promedio que alcanzan las sentencias condenatorias, a fin de evaluar su incidencia en el mercado asegurador. Ante este estado de situación y ante la probabilidad de un desborde cuantitativo de los riesgos que normalmente explota, para prevenir la posibilidad de que su patrimonio quedara comprometido más allá del límite técnicamente tolerable, no optó por ninguna de las alternativas que le permitian fraccionar los riesgos, sino que prefirió contratar fijando una franquicia irrazonablemente alta". Concluyó que "la cláusula contractual pactada resulta nula de nulidad absoluta, pues la franquicia irrazonablemente alta acordada -que deja sin cobertura a la casi totalidad de la víctimas en caso de siniestro convierte en un mero formalismo la emisión de la póliza y vulnera el principio de buena fe, en tanto importa convalidar la ilícita eximición del asegurador mediante una suerte de cláusula exonerativa o limitativa de su obligación de indemnizar el siniestro hasta determinada suma, sin atender a la función social del seguro y a la protección del tercero damnificado”.

68 "Corresponde desestimar la queja interpuesta contra la sentencia que declaró la nulidad absoluta de la cláusula que limitaba la responsabilidad de la aseguradora en la medida de la franquicia del seguro, pues, aun cuando la ley considera que la oponibilidad de la franquicia es la regla-art. 109 de la ley 17.418-, ello no impide discriminar entre la diversidad de situaciones que puedan plantearse y reconocer-como en el caso-cuando se ha estipulado una franquicia que afecta el acceso a la reparación de los daños sufridos por la víctima del accidente, principio de raíz constitucional por cuya tutela corresponde velar a los magistrados" (de la sentencia de la Corte según la doctrina sentada en "Ortega" -20/10/2009, LA LEY 2010-A , 304-, a la cual remite, CSJN, 07/02/2012, Tarzari, María Florencia y otro c. Poder Ejecutivo Nacional y otros s/daños y perjuicios, LLOnline, AR/JUR/714/2012). 
mente- en la autoridad de la Superintendencia de Seguros de la Nación, la fijación de su contenido, no puede desconocerse que, resultando la finalidad última del seguro automotor obligatorio la protección de las víctimas de los accidentes de tránsito, toda franquicia conspiraría contra la misma y desnaturalizaría, por ello, la finalidad protectoria de este especial seguro. Así lo ha sido reconocido en la legislación de la Comunidad Europea mediante las sucesivas directivas que fijan la inoponibilidad de las franquicias.

La reciente normativa dictada por la Superintendencia de Seguros de la Nación para el seguro de responsabilidad civil que cubre al autotransporte público de pasajeros, vigente desde el $1^{\circ}$ de setiembre de $2017^{69}$, fija la franquicia en $\$ 120.000$, pero la declara inoponible a la víctima (a nuestro juicio, violando la norma del art. 118 de la Ley de Seguros y, por ende, la norma constitucional del art. 31 que delinea la pirámide del orden jurídico argentino).

Sin embargo, resulta imperioso el tratamiento legislativo de un proyecto de seguro automotor obligatorio cuyo contenido se autoabastezca, teniendo en cuenta las enriquecedoras experiencias del derecho comparado y también las recogidas en nuestro medio merced a variados proyectos de ley. En lo esencial, debe contener un régimen de pronto pago, con límites económicos de cobertura, fundado en la responsabilidad objetiva y agravada del automovilista o transportista, con limitadísimas exclusiones de cobertura que permitan una protección amplia, con un fondo de garantía que asegure que todos accedan a la indemnización y, por supuesto, sin franquicia que obstaculice la adecuada indemnización de la víctima del daño ${ }^{70}$.

69 Resolución 38218 SSN del 20 de febrero de 2014, anexo I, cláusula 2. Se podrá argüir que merced a la inflación reinante ese monto ha quedado sensiblemente desactualizado respecto de similar monto que fuera establecido originariamente en 1997, sin embargo, ello no impide considerar su injusticia respecto de la víctima del daño provocado por un auto transportista cuando resulte menor a esa cuantía ya que, a pesar de la existencia de una obligación legal de contratar un seguro, carecerá para esa hipótesis de la protección del seguro automotor obligatorio.

70 Ver el Anteproyecto de Limitación Cuantitativa del Daño y Seguro Obligatorio contra la Responsabilidad Civil por accidentes de automotores publicado en la obra de su autor: Stiglitz, Rubén S., "Teoría y Práctica del Derecho de Seguros", Ed. La Ley, Buenos Aires, ps. 596 y siguientes. 


\section{SUMA ASEGURADA}

\section{a) La suma asegurada como limite de la obligación del asegurador. Suficiencia. Sublimites}

Sabido es que, como derivación inescindible de la asunción del riesgo por el asegurador, resulta su obligación principal que se halla constituida por el resarcimiento del daño o el cumplimiento de la prestación convenida si ocurre el evento previsto (arts. $1^{\circ}$ y 61, L.S.) $)^{71}$. Tanto el resarcimiento como el cumplimiento de la prestación convenida se traducen en una única expresión: pago que, como tal, integra el objeto del contrato y en el caso del seguro porta un límite constituido, en principio, por la suma asegurada $^{72}$ "salvo que la ley o el contrato" dispongan lo contrario (art. 61, L.S.).

En consecuencia, en una primera aproximación, puede afirmarse que la obligación principal del asegurador se halla configurada por el pago de la suma asegurada hasta el límite acordado por las partes. En los seguros de daños patrimoniales el pago de la suma asegurada se hallará constituido por el daño patrimonial provocado en relación de causalidad adecuada $^{73}$ por el siniestro en la medida o hasta el monto de la suma asegurada (art. 61-1 y 2, L.S.) ${ }^{74}$.

En los seguros contra la responsabilidad civil, la suma asegurada constituye el "quantum" máximo por el que debe responder el asegurador por cada siniestro que pudiere acaecer durante la vigencia del contrato de seguro, cualquiera resulte el número de responsables o la forma de la reparación o la diversidad de los daños que acaezcan. Todos ellos conforman el siniestro único ${ }^{75}$.

71 CNCom., Sala A, 13/10/1986, “La Construcción Cía. de Seg. c. Christiani Nielsen”, La Ley, 1987-C, 51; DJ, 1987-2-639.

72 CNCom., Sala A, 20/7/1995, "Páez, M. c. El Comercio Cía. de Seg.” (inédito).

73 Cám. Com. Cap., 15/10/1937, “Giulianetti, N. c. La Inmobiliaria Cía. de Seg.”, La Ley, 8-836.

74 De allí que se tenga decidido que la obligación del asegurador por un seguro de incendio no se extiende a los daños que ese siniestro provoque a terceros (SCBA, 19/8/1993, "Artola, A. c. Zagrodny, A.", DJBA, 145-5427).

75 Veiga Copo, Abel B., Los principios de derecho europeo del contrato de seguro, Pontificia Universidad Javeriana-CEDEP-Grupo Editorial Ibañez, Colección Prospectivas del Derecho $n^{\circ} 2$, Bogotá, 2012, p. 405. 
La frase "suma asegurada" comprende el capital de condena. Más adelante discurriremos sobre la suerte de los intereses. A su vez, en el seguro contra la responsabilidad civil, los accesorios están conformados por los gastos y honorarios previstos en los artículos 110 y 111, L.S.

La expresión "en la medida o hasta el monto de la suma asegurada" expresa: (a) los alcances del derecho del asegurado y la obligación principal del asegurador (b) tal como lo han acordado las partes en el marco de la autonomía de la voluntad al que le sirve de límite el (c) principio resarcitorio que impide admitir, por reprochable, (d) el enriquecimiento sin causa del asegurado ${ }^{76}$.

En particular, en el seguro contra la responsabilidad civil, la obligación principal siempre se halla constituida por el pago, en el caso, de lo que se deba a un tercero en razón de la responsabilidad prevista en el contrato, expresión que debe entenderse (equivalente) a suma asegurada ${ }^{77}$. En el sentido indicado, cabe afirmar que "cualquiera sea el alcance de la sentencia dictada en una acción de daños y perjuicios, su ejecución contra el asegurador citado en garantía no puede exceder el límite de la cobertura, pues el artículo 118 de la Ley de Seguros sólo reconoce el derecho de ejecutar la sentencia a su respecto en la medida del seguro, efecto limitado que rige también en el supuesto en que la citación sea pedida por la víctima, como que lo sea por el propio asegurado" 78 .

En síntesis, la función de la suma asegurada señalada en la póliza, indica el monto máximo que debe pagar el asegurador ${ }^{79}$, no determinando

76 CNCom., Sala D, 14/4/1998, “Kadrimar S.A. c. Suizo Argentina Cía. de Seg.”, DJ, 1999-1-448.

77 Por ello, señalamos que la definición del seguro contra la responsabilidad civil que surge de la lectura del art. 109, L.S., debe leerse así: El asegurador se obliga a mantener indemne el patrimonio del asegurado por cuanto deba pagar a un tercero en razón de la responsabilidad prevista en el contrato, a consecuencia de un hecho acaecido en el plazo convenido.

78 CCiv y Com, Rosario, Sala III, 7/5/2010, "Municipalidad de Rosario c/Emp. Transp. Pasajeros", LLLitoral, 2010, octubre, pág. 1039. En el mismo sentido, CN Civil Sala I, 14/5/2015, “ADJ c/VCA”, RC y S., octubre del 2015, pág. 248, donde se dispuso que "el asegurador se obliga a mantener indemne al asegurado por cuanto deba a un tercero en razón de la responsabilidad prevista en el contrato. En virtud de ello, las obligaciones que se atribuyan al asegurador no deben serle impuestas más allá de los términos pactados en la póliza, pues la misma ley establece que el contrato es la fuente de sus obligaciones, y en dicho instrumento se determinan los alcances y límites de la garantía debida".

79 CN Com Sala E, 30/11/2011, "Fedele C. c/Seguros Bernardino Rivadavia", ED: 2012/05/11, 9 
el valor a indemnizar, sino que exige del asegurado la prueba del daño efectivamente sufrido ${ }^{80}$.

La obligación que asume el asegurador es la de mantener indemne el patrimonio del asegurado. La indemnidad atiende a la acepción que la identifica como un "estado o situación del que está libre de padecer daño o perjuicio" ${ }^{\prime}$. Apunta conceptualmente al mantenimiento de la integridad o incolumidad del patrimonio del asegurado ${ }^{82}$.

Ahora bien, esa indemnidad es debida por el asegurador en la medida del daño irrogado y hasta el límite de la suma asegurada. Por cierto, es el asegurador quien invoca tal limitación sobre quien pesa la carga de la prueba de su existencia (art. 377 Cód. Procesal).

La Corte Suprema de Justicia de la Nación tuvo oportunidad de pronunciarse, recientemente ${ }^{83}$, sobre la cuestión del límite de la condena al asegurador en el seguro contra la responsabilidad civil.

La Sentencia de la Sala M de la Excma. Cámara Nacional de Apelaciones en lo Civil había confirmado la sentencia de primera instancia en cuanto extendía al asegurador la condena dictada contra el establecimiento educativo, aún en exceso de la cobertura asegurativa que, en el caso, alcanzaba la suma de $\$ 100.000$ por persona damnificada.

Para decidir en esa forma, el Tribunal de Alzada sostuvo que la aseguradora no había invocado dicho límite de cobertura en la oportunidad de la contestación de la citación en garantía, sino al agraviarse de la sentencia de primera instancia, por lo que admitirlo en la segunda instancia violaría el principio de congruencia.

Por su parte, la Corte sostuvo que había cuestión federal bastante para el examen de la causa en orden a que la excepción correspondía cuando

80 CNCom., Sala C, 15/7/1997, "Agencia de Cambio Florida c. Cenit Cía. de Seg.", La Ley, 1997-E, 1043 (39.914-S); CNCom., Sala C, 12/2/1997, “Maman, O. G. c. Paraná Cía. de Seg.”, La Ley, 1997D, 875, jurisp. agrup., caso 11.735 .

81 Diccionario de la lengua española, $20^{\mathrm{a}}$ ed., pág. 766.

82 Signorino Barbat, Andrea, Los seguros de responsabilidad civil, Fundación de Cultura Universitaria, Montevideo, 2011, p. 80.

83 CSJN, 10.11.15, "Fernández, Gustavo Gabriel y ot. c/ Gobierno de la Ciudad de Buenos Aires y ot. s/ Daños y perjuicios". 
“...los jueces asignan a las cláusulas del contrato un alcance reñido con la literalidad de sus términos y la clara intención de las partes, y omite ponderar argumentos conducentes para la correcta solución del pleito (Fallos: 312:1458)".

Destacó la existencia de un peritaje contable en el expediente que daba cuenta (bajo el acápite de "cualquier otro dato de interés"), de la existencia de un límite de cobertura de $\$ 1.000 .000$ por evento y $\$$ 100.000 por persona, señalando que ello no había sido impugnado por la parte actora.

Asimismo, consideró que la aseguradora al contestar la citación en garantía había sostenido que “...no cabe duda de su legitimación pasiva cuando de lo que se trata es de cumplimentar la obligación de mantener indemne al asegurado. Pero dicha obligación debe surgir de la existencia de un contrato de seguro vigente al momento del siniestro por el cual se reclama y siempre dentro de sus propias previsiones". En razón de ello, concluyó que condenarla en exceso del límite de cobertura resultaría contrario a lo establecido en el art. 118 de la Ley de Seguros.

Cerró la argumentación indicando que la causa de la obligación resulta ser el contrato convenido entre las partes y que fue en virtud de dicho convenio que la empresa aseguradora fue traída a juicio, en la oportunidad prevista por el ordenamiento procesal vigente, por lo que la ausencia de un específico señalamiento del límite de la cobertura no impide su admisión cuando el mismo se encuentra debidamente acreditado en la causa mediante la prueba ofrecida y producida regularmente ${ }^{84}$.

Como consecuencia de ello, dejó sin efecto la sentencia impugnada y ordenó al tribunal de origen proceda a dictar un nuevo fallo con arreglo a lo precisado por la Corte Suprema de Justicia.

84 El máximo Tribunal ya ha establecido que las obligaciones que se atribuyen al asegurador no deben serle impuestas más allá de los términos pactados en la póliza, pues la misma ley 17.148 (nuevamente, el art. $118,3^{\circ}$ párr. señala que la sentencia hará cosa juzgada respecto al asegurador y puede ejecutarse contra él en la medida del seguro) establece que el contrato es la fuente de sus obligaciones y en dicho instrumento se determinan los alcances y límites de la garantía debida (CSJN, "Fallos" 322:653). 


\section{b) Suficiencia de la suma asegurada. Sub-limites. Su cuestionamiento}

En un reciente fallo dictado por la Sala "C" de la Cámara Nacional en lo Civil se estableció que "... si bien es cierto que el contrato de seguro es esencialmente concertado para mantener la indemnidad patrimonial del asegurado, la imposición legal de su celebración pretende resguardar el patrimonio de terceros ajenos al acuerdo de voluntades. Con lo cual, el centro de protección del negocio jurídico y sus efectos económicos se han trasladado virando hacia los eventuales damnificados por los accidentes de tránsito, para quienes el seguro contra la responsabilidad civil cumple una función de garantía en la efectiva percepción de la indemnización del daño" ${ }^{85}$.

Fue este uno de los fundamentos que utilizó la Sala para dejar sin efecto el límite máximo de responsabilidad del asegurador, representado por la suma de $\$ 3.000 .000$ como frontera terminal del tope de responsabilidad exigible a aquel.

El fallo hizo referencia a “...la Ley Nacional de Tránsito que impuso la necesidad de un seguro obligatorio de responsabilidad civil frente a terceros por los eventuales daños que pudiera ocasionar el dueño o guardián del automóvil, y dispone asimismo que su contratación debe realizarse de acuerdo a las condiciones que fije la Superintendencia de Seguros de la Nación (conf. art. 68, ley 24.449). Dentro de este régimen, $y$ en virtud de la delegación efectuada por la referida ley, la Superintendencia de Seguros de la Nación dictó, la Circular $n^{\circ} 2819$, de fecha 3 de mayo de 1993, mantenida por Resolución $n^{\circ} 35.863$ del 10 de junio de 2011, antes referidas".

Si bien la sentencia dictada razonó que "cuando se trata de analizar los alcances de un seguro obligatorio, toda cláusula restrictiva deberá ser interpretada estrictamente”, a continuación, afirmó que “...los límites cuantitativos de cobertura, en sí mismos, no son ni antijurídicos ni irrazonables. Sin embargo, cuando un precepto frustra o desvirtúa los

85 CNCivil, Sala C, 26.05.16, "Aimar, María C. y ot. c/ Molina, José A. y ots. s/ daños y perjuicios (acc. trans. c/ les. o muerte)y "Aldasoro y Compañía S.A y otro c/ Molina, Jose Alfredo y otros s/ daños y perjuicios (acc. trans. sin lesiones)", acumulado al primero. (elDial.com - AA999B). 
propósitos de la ley en que se ha inserto, de modo tal que su aplicación torne ilusorios derechos por ellos consagrados, le es lícito al juzgador apartarse de tal precepto y dejarlo de aplicar a fin de asegurar la primacía de la Ley Fundamental, como medio de afianzar la justicia que está encargado de administrar (CSJN, Fallos 308:857; 311:1937)”.

Asimismo, la Cámara sostuvo que "a la postre, cabe determinar si la cláusula cuestionada por la parte actora, en los términos en que ha sido pactada, ha o no desnaturalizado la utilidad social del instituto del seguro, propósito querido por la ley al establecer su obligatoriedad. La razonabilidad es invocada como un instrumento para individualizar la solución más adaptable a los tiempos y a las circunstancias, la más lógica y la que da mejores respuestas a las exigencias económico-sociales del momento".

La sentencia reprochó al asegurador que “...en ocasión de celebrar el respectivo contrato de seguro, no pudo ni debió desconocer la tumultuosa actividad litigiosa derivada de la alta siniestralidad automovilística, $n i$ tampoco el monto promedio que alcanzan las sentencias condenatorias en caso de lesiones incapacitantes, que en reiteradas ocasiones superan los \$3.000.000”...En la especie, el límite de cobertura convenido entre asegurador y asegurado se ha convertido en un obstáculo para que el damnificado pueda obtener en tiempo oportuno el resarcimiento que la normativa civil consagra a su favor y que hoy se ve reforzada tras la incorporación de los tratados internacionales que se han sumado así al bloque de derechos constitucionales que protegen a la persona humana, su saludy su integridad física, psíquica y estética, a través de la recepción que de aquéllos ha hecho el inciso 22 del artículo 75 de la Constitución Nacional. Su operatividad no atañe sólo al Estado sino también a los particulares y ello ha implicado ensanchar el enfoque meramente patrimonialista del Código Civil, considerando a la salud, la integridad y la vida como valores en sí mismos".

Por otro lado, el fallo no desconoce que la cláusula en cuestión fue redactada de conformidad con lo normado por la Circular n ${ }^{\circ} 2819$ de la Superintendencia de Seguros de la Nación, de fecha 3 de mayo de 1993, mantenida por Resolución n 35.863 del 10 de junio de 2011, pero señala "su falta de modificación pese a los notorios cambios que sufriera 
la coyuntura económica de nuestro país durante esos casi veinte años. Tal disposición impone un límite máximo de cobertura de \$3.000.000, contrariando en consecuencia, según quedó dicho, la propia ley que reglamenta, en cuanto a su espíritu y su teleología”.

Por cierto, el análisis del fallo no puede omitir que el Tribunal invoca la normativa de Defensa de los Consumidores y Usuarios al señalar que “... a partir de la sanción de la Ley de Defensa del Consumidor, se exhibe un régimen de control judicial sustentado sobre las siguientes bases: 1.- se introducen dos cláusulas abiertas que presuponen, por sí mismas, sendas definiciones de cláusulas abusivas (las que desnaturalicen las obligaciones y las que importen renuncia o restricción a los derechos del consumidor; 2.- se enuncian sólo dos cláusulas abusivas (las que limitan la responsabilidad por daños y las que contengan cualquier precepto que imponga la inversión de la carga de la prueba en perjuicio del consumidor); 3.- se dispone como efecto previsto para las cláusulas abusivas, la declaración de nulidad de las mismas: "Sin perjuicio de la validez del contrato, se tendrán por no convenidas...(art. 37)”...Y al respecto se ha sostenido que "la sanción prevista por la normativa en análisis para el supuesto en que el contrato contemple una cláusula vejatoria en desmedro del consumidor determina, ya en un principio, que las obligaciones que emerjan de dicha previsión no podrán ser exigidas al consumidor. Pero, para que esto sea posible, no será necesario que la parte débil de la relación contractual invoque judicialmente la nulidad de dicha cláusula, sino que ésta podrá ser declarada por el juez de oficio, y planteada por cualquier interesado en su declaración de invalidez".

La conclusión de tales consideraciones no es otra que la desviada interpretación por la que se pregona que "el seguro fue pergeñado por el legislador para defender a la víctima, quien se erige como un consumidor de seguros. Pues ella es indudablemente el epicentro de la relación jurídica que ha unido al asegurado con su aseguradora”.

A renglón seguido, el epílogo es que “... el límite máximo de cobertura que invoca la aseguradora, ha desnaturalizado la utilidad social del instituto del seguro de responsabilidad civil, propósito querido por la ley al establecer su obligatoriedad. De admitírselo, la sentencia indemnizatoria se convertiría en letra muerta, porque el demandado no 
podría hacer frente a la elevada responsabilidad patrimonial que el órgano jurisdiccional le endilga...La razonabilidad es invocada como un instrumento para individualizar la solución más adaptable a los tiempos y a las circunstancias, la más lógica y la que da mejores respuestas a las exigencias económico-sociales del momento...En tal inteligencia, carece de razonabilidad crear un sistema hermético de responsabilidad que produzca fallos impecables con resarcimientos justos, pero que resulten incobrables por ser el responsable insolvente".

Por cierto, el fallo reseñado es contradictorio con el precedente fundamental de la Corte Suprema de Justicia de la Nación en materia de seguros de los últimos tiempos ${ }^{86}$.

En ese pronunciamiento, el máximo Tribunal de Argentina, señaló que, “....sin perjuicio de señalar que el acceso a una reparación integral de los daños sufridos por las víctimas de accidentes de tránsito constituye un principio constitucional que debe ser tutelado, y que esta Corte Suprema ha reforzado toda interpretación conducente a su plena satisfacción, ello no implica desconocer que el contrato de seguro rige la relación jurídica entre los otorgantes (arts. 1137 y 1197 del Código Civil) y los damnificados revisten la condición de terceros frente a los mismos porque no participaron de su realización, por lo que si desean invocarlo deben circunscribirse a sus términos".

A renglón seguido el Máximo Tribunal afirmó que "la función social que debe cumplir el seguro no implica, empero, que deban repararse todos los daños producidos al tercero víctima sin consideración a las pautas del contrato que se invoca, máxime cuando no podía pasar inadvertido para los damnificados que estaban viajando en un lugar no habilitado para el transporte de personas y que de tal modo podían contribuir, como efectivamente ocurrió, al resultado dañoso cuya reparación reclaman".

Ratificó que, “...la oponibilidad de las cláusulas contractuales ha sido el criterio adoptado por el tribunal en los supuestos de contratos

86 CSJN, 08.04.14, "Buffoni, Osvaldo O. c. Castro, Ramiro M. s/ daños y perjuicios, publicado: SJA 14/05/2014, 38; SJA 2014/05/14-38; JA 2014-II, 746; Abeledo Perrot No: AR/JUR/6035/2014. 
de seguro del transporte público automotor" (Fallos: 329:3054 y 3488; 331:379, y causas O.166. XLIII. "Obarrio, María Pía c. Micrómnibus Norte S.A. y otros” y G.327.XLIII. "Gauna, Agustín y su acumulado c. La Economía Comercial S.A. de Seguros Generales y otro”, sentencias del 04/03/2008)".

Además la CSJN se refirió a la prelación normativa de las leyes de Seguros y Defensa de los Consumidores y Usuarios, aclarando "que no obsta a lo dicho la modificación introducida por la ley 26.361 a la Ley de Defensa del Consumidor, pues esta Corte ha considerado que una ley general posterior no deroga ni modifica, implícita o tácitamente, la ley especial anterior, tal como ocurre en el caso de la singularidad del régimen de los contratos de seguro (M.1319.XLIV "Martínez de Costa, María Esther c. Vallejos, Hugo Manuel y otros s/ daños y perjuicios", fallada el 09/12/2009)".

Como agudamente, señala Traverso ${ }^{87}$, cabe advertir que los redactores del nuevo Código Civil y Comercial delimitaron la problemática de la reparación económica de los daños señalando que “...Uno de los aspectos más controvertidos de la regulación propuesta por el Proyecto de 1998 en materia de daño fue la existencia de limitaciones cuantitativas (artículo 1634)...Para aclarar este punto conviene hacer algunas precisiones: a) la indemnización del daño nunca es integral, porque no coincide el daño "real" con el "jurídico". Si hay algo que pueda ser denominado "real", comprende muchos aspectos que para el legitimado del derecho son importantes, pero el sistema jurídico excluye. Por ejemplo, hay un régimen de causalidad que no cubre todas las consecuencias, sino sólo las previsibles porque hay que valorar la posición del agente. También hay limitaciones dificiles de superar, como ocurre, por ejemplo, con la indemnización dineraria que nunca puede conformar la desaparición de un ser querido; b) la indemnización, a su vez, tiene relación con los distintos subsistemas en los que se aplica y hay numerosos supuestos en los que hay límites en el derecho vigente. Además, muchos de ellos provienen de convenios internacionales, como ocurre, por ejemplo, en materia de transporte aéreo; c) en otros casos, hay diferentes modos

87 Traverso, Amadeo E., "La medida del seguro en la cobertura del riesgo de responsabilidad civil automotor y "La canción del pirata", el Dial DC21E7, 22/09/2016. 
de solucionar un mismo problema, como sucede con los accidentes de la circulación: unos países lo incluyen en la seguridad social, otros lo cubren con el seguro de primera persona, otros lo regulan mediante la responsabilidad civil, la mayoría con límites en la cobertura...Frente a toda esa variedad y, teniendo en cuenta la tradición argentina en la materia, se ha decidido consagrar, como principio general, la reparación plena. Como todo principio, debe lograrse su satisfacción en la mayor medida posible, lo que no es incompatible con que, en situaciones delimitadas, pueda armonizarse con otros principios y establecerse una limitación por medio de leyes especiales”.

En resumen, la finalidad de las normas comprometidas en la cuestión no es otra que el reconocimiento del régimen legal del Contrato de Seguro como uno de los microsistemas normativos autosuficientes que es respetado tanto por la sanción del nuevo Código como por la vigencia de la Ley General de Defensa de los Consumidores y Usuarios.

El fallo de la Sala C de la Cámara Civil tuvo continuidad en otro pronunciamiento de la Sala A de la misma Cámara ${ }^{88}$ que cuestionó los sublímites establecidos en la póliza de seguro. En efecto, en el caso, la citada en garantía había invocado un sub-límite de cobertura que ascendía a la suma máxima de $\$ 125.000$ por persona afectada no transportada, en relación a los daños corporales o muerte ocasionadas. En la ocasión el Tribunal sostuvo: "Tratándose el seguro de responsabilidad civil de un contrato de consumo, se aplica el art. 37 de la ley 24.240, por lo tanto, corresponde concluir que la aseguradora debe responder por un accidente de tránsito sin considerar los límites establecidos en la póliza, ya que el monto allí previsto, en el caso, es irrazonable para afrontar los acontecimientos juzgados, que lo superan holgadamente...La cláusula de limitación de responsabilidad establecida en el contrato de seguro es inoponible, en tanto la suma establecida como límite de cobertura resulta tan reducida que afecta el principio de la buena fe que debe primar en la celebración, interpretación y ejecución de los contratos y vulnera el principio de moralidad del objeto de los actos jurídicos-arts. 953, 1167 y 1198 del Cód. Civil; arts. 279, 958, 961,1004 y 1061 del Cód. Civil y Comercial-...El

88 CNCivil, Sala A, 22/09/2016, M., C. D. y otro c. M., M. M. y otros s/ daños y perjuicios, RCyS2016XII, 221 - LA LEY 01/02/2017, 9, Online: AR/JUR/70765/2016. 
límite de cobertura fijado en la póliza del seguro — $\$ 125.000$ y 30\% de la condena en costas - no es lógico ni razonable ya que sería un supuesto de "no seguro", por insuficiencia de la suma; elimina uno de los propósitos dominantes o principales de la cobertura, que no es tan solo garantizar la indemnidad del asegurado, sino, en especial, resarcir el daño provocado al damnificado, produciendo un quiebre al principio de confianza y buena fe, basamento de una sociedad civilizada, dañando el marco de credibilidad de la sociedad, y en especial, de los consumidores de seguros ...L a finalidad tenida en cuenta por el art. 68 de la ley 24.449, que establece el seguro automotor obligatorio, que no es otra que la de proteger a las víctimas de accidentes de tránsito y asegurar su reparación, se vería claramente desvirtuada por la aplicación de una resolución administrativa, fundada en una cláusula contractual abusiva, que prevé la posibilidad de limitar la cobertura a un monto irrisorio, por lo que debe ser dejada de lado en los términos de los arts. 28, 31 y cc de la Constitución Nacional”.

Resulta claro pues que el diseño del seguro obligatorio automotor en Argentina no satisface el sentido de justicia que aplican sus jueces y ha terminado por poner en pugna los límites del contrato de seguro como "remedio" a la anomalía. La tensión entre la cuantificación económica de la responsabilidad civil y los límites del seguro se resuelve, insatisfactoriamente, desconociendo estos últimos, mientras persiste la mora legislativa.

\section{c) Los intereses y la inflación}

La cobertura asegurativa se extiende a los intereses debidos por la mora en el pago del siniestro, pues, de no incluírselos, podría darse el caso de que el retardo o resistencia extrajudicial o judicial del asegurador perjudique sólo al titular del interés asegurable, lo cual configuraría una prerrogativa vedada y privada de efectos conforme lo dispuesto por el art. $344 \mathrm{CCyCN}$ y contraria al principio de buena fe (art. 9) ${ }^{89}$.

En el contrato de seguro, el límite de cobertura está dado por la suma en concepto de capital y los intereses que como accesorio de dicho capital

89 Cámara de Apelaciones en lo Civil y Comercial Contencioso administrativo de San Francisco, Ibarra, María Cecilia c. Acosta, Estefanía Victoria y otros/ ordinario - daños y perjuicios, 11/10/2012, LLC 2013 (abril), 340, AR/JUR/70974/2012. 
se devengaron a partir de allí y constituyen los mayores daños provenientes del incumplimiento de la obligación de dar dinero a cargo del asegurador ${ }^{90}$. Ambos integran el monto de la condena y se encuentran dentro de los límites de la cobertura que cabe exigirle a la citada en garantía, en tanto optó por controvertir el reclamo, demorando en el tiempo la solución del conflicto ${ }^{91}$.

En períodos de inflación y hoy ante la imposibilidad jurídica de indexar (arts. 7 y 10, ley 23.928, ratificados por la Ley de Emergencia Económica), frente a la mora del asegurador la suma debida no queda plenamente satisfecha con los intereses moratorios aún con la aplicación de la tasa activa, ya que este no constituye más que un método indirecto de apreciación de la moneda, dado que un porcentaje de su tasa enjuga la inflación. Pero habrá de tenerse presente que la depreciación de la moneda ocurrida desde que la obligación debió ser satisfecha, hasta el efectivo pago, o sea, mediando mora, es fundamento suficiente para sostener que se trata de un presupuesto del daño ${ }^{92}$. En efecto, integra el daño resarcible al acreedor, aunque supere el límite de la suma asegurada. De allí que corresponde que en caso de mora se apliquen intereses, aunque debido a ello se exceda el límite de la suma asegurada, y aunque no exista inflación. Sólo basta con la mora del asegurador.

\section{d) Las costas también integran la garantía a cargo del asegurador}

Si el asegurador asume la dirección del proceso civil, debe el pago de los gastos y costas, judiciales y extrajudiciales (art. 110, inc. a], L.S) ${ }^{93}$. Esta disposición se ve complementada con la vigente en las condiciones

90 Castro Sanmartino, Mario. E.-Schiavo, Carlos A., Seguros, Lexis Nexis, Buenos Aires, 2007, p. 299.

91 CNCiv., Sala B, 26/04/2012. - C., J. y otros c. Turismo Río de la Plata y otros s/daños y perjuicios (acc. trans. c/les. o muerte), ED 14/09/2012, nro 13.080.

92 En caso de mora del asegurador corresponde computar los efectos de la depreciación monetaria al determinar la indemnización proveniente de un contrato de seguro (CNCom., en pleno, 29 11 78, Mussa de Gómez de La Vega, Maria H. c. La Defensa, Cía. de Seguros Generales, S. A.). En los fundamentos del voto de Morandi puede leerse que, como resultado del desfasaje producido por la inflación, "en el "seguro de responsabilidad civil" (sea con límite o sin límite), las indemnizaciones a satisfacer a los damnificados son apreciadas de acuerdo con el "minus valor" adquirido por la moneda, lo que equivale a decir que la cifra a pagar por este concepto en un siniestro por parte del asegurador, será notoriamente superior a la que en fecha pretérita, se tomó como base del cálculo de la prima por igual importancia de perjuicios habidos".

93 Meilij, Gustavo R., Manual de Seguros, Depalma, Buenos Aires, 1994, p. 111. 
generales de póliza para vehículos automotores y/o remolcados y de seguro contra la responsabilidad civil, de la siguiente manera:

a) Cuando los montos pretendidos por la víctima sean inferiores o iguales a las coberturas contratadas: en su totalidad;

b) Cuando fueren superiores: en la proporción resultante de la comparación del monto cubierto con el que pone fin al proceso; el saldo quedará a cargo del asegurado ${ }^{94}$.

Si el asegurador no asume la dirección del proceso, o la declina una vez asumida, el pago de los gastos y costas lo debe en la medida en que fueron necesarios (art. 111, L.S.).

Si el asegurador asume la dirección del proceso penal, debe las costas.

Si el asegurado asume su defensa penal, las costas son a su cargo (arg. art. 110, inc. b], L.S.). Si en el proceso penal se deduce una pretensión civil, rige para una y la otra lo dispuesto precedentemente.

Finalmente, cuando el importe demandado exceda la cobertura contratada, situación en que el asegurado y/o conductor pueden participar también en la defensa con el o los profesionales que designen al efecto, las costas serán a cargo de aquéllos, en lo que a dicha defensa participativa se refiere (cláusula de defensa en juicio de las condiciones generales de la póliza de seguro obligatorio y de seguro voluntario automotor).

En síntesis, la regla proporcional consiste en que, si el asegurado debe soportar una parte del daño, el asegurador reembolsará los gastos y costas en la misma proporción ${ }^{95}$. El principio precedente tiene aplicación, obviamente, aun cuando la pretensión sea desestimada y/o las costas deban ser soportadas en el orden causado ${ }^{96}$.

94 En ese sentido se tiene expresado que en el caso de un seguro que ampara el riesgo de accidente de trabajo, cuando la indemnización debida al tercero exceda en sí propia del máximo asegurado, los gastos y las costas serán soportados proporcionalmente por el asegurado y por el asegurador (CNCom., Sala D, 25/8/1995, “Cattorini Hnos. S.A. c. El Cabildo Cía. de Seg.”, JA, 1996-II-645).

95 CNTrab., Sala VII, 21/4/1988, “Gauna, E. c. Tisera, C.”, JA, 1989-IV-síntesis.

96 La Cám. Civ. y Com. Mar del Plata tuvo ocasión de pronunciarse en un fallo inédito sobre el particular: el asegurador declinó la dirección de un proceso donde la pretensión superaba la cobertura de responsabilidad civil hacia terceros. El director del proceso fue el asegurado, quien para ejercitarlo 


\section{e) La excepción: proceso mantenido por decisión manifiestamente injustificada del asegurador y la aplicación integra de las costas}

La regla proporcional prevista por el artículo 111, Ley de Seguros sufre una excepción: si las costas se devengaron en causa civil mantenida por decisión manifiestamente injustificada del asegurador, éste debe pagarlas íntegramente (art. 111-3, L.S.).

A ello aludió expresamente en el caso, el asegurador recurrente, para ratificar la vigencia de la regla general: es el asegurado quien carga con la parte proporcional de los gastos y costas en caso de hacerse cargo de una parte del capital.

Este principio no sólo recepta la posición doctrinaria concreta sobre el tema en examen, sino que integra la medida del resarcimiento adeudado por el asegurador al asegurado, en las pretensiones de responsabilidad derivadas de la inejecución por el primero de su obligación gestoría y, por ende, la de mantener indemne al segundo ${ }^{97}$.

Sobre esta cuestión, ante un recurso interpuesto por el asegurador con motivo de habérsele impuesto el pago total de las costas, se decidió la aplicación de lo dispuesto por el artículo 111, tercer párrafo, el que dispone: "Si se devengaron en causa civil mantenida por decisión manifiestamente injustificada del asegurador, éste debe pagarlas integramente”. Y ello en razón de que el referido pago total de las costas por el asegurador está condicionado a que se devenguen en causa civil mantenida por decisión

particularmente designó letrado. La pretensión fue desestimada con costas y el asegurado en juicio ulterior pretendió del asegurador el reembolso del total, sin consideración a la regla proporcional. Con voto del doctor Solari Brumana se resolvió: "Considero que conforme al texto transcripto del art. 23 de las condiciones generales, el debate doctrinario acerca de si aquéllos (los gastos o costas causídicos) son o no asimilados a los de salvamento, carece de importancia porque las partes convinieron claramente que en ningún supuesto dejaría de regir respecto de las costas la llamada regla proporcional. Corrobora mi opinión lo dispuesto en el segundo párrafo del art. 111 de la ley $17.418 \ldots$ De modo que como la aseguradora hubiera debido soportar sólo una parte del daño está sólo obligada a reembolsar los gastos causídicos abonados por el asegurado en la misma proporción (art. 111, 2do. párr., ley 17.418)" (exp. 23.153, "Munuera, C. c. Coop. de Seguros Bernardino Rivadavia s/cobro de pesos", 26/8/1969).

97 Picard y Besson sostienen que si el asegurador, ejerciendo la dirección del proceso, compromete costas abusivas, ellas pueden en razón de esos abusos ser puestas a su cargo al margen de la suma asegurada (Picard, M. - Besson, A., Les Assurances terrestres", LGDJ, París, 1982, T. I, No 356, pág. 528). 
manifiestamente injustificada del asegurador. En ese caso -se sostuvo-, "el asegurador se opuso a la pretensión de la parte actora alegando que el asegurado no era propietario del vehículo generador del siniestro, y por tanto no le incumbía su responsabilidad como asegurador. Es de resaltar que tal actitud oponente, y ante las pruebas de autos, su actuar configura una posición manifiestamente injustificada y que entra por cierto en la órbita de aplicación del supuesto en estudio. Además, cabe resaltar que es de aplicación al sub lite la disposición del artículo 2294 del Código Civil y que la ley no hace más que concretarlo al caso del contrato de seguro. La responsabilidad del asegurador cuando dirige el proceso judicial o extrajudicial, si hace operaciones riesgosas que el titular no acostumbrara hacer o si mira más por sus intereses que por los del asegurado es tal que la ley pone a cargo del asegurador las consecuencias del proceso judicial o extrajudicial, aun superada la suma asegurada"98.

\section{f) Los intereses y las costas. Regla proporcional}

En otro todavía más reciente pronunciamiento, la Corte Suprema de Justicia de la Nación se ocupó de la regla proporcional en materia de intereses y costas en el régimen del seguro contra la responsabilidad civil ${ }^{19}$.

En primera instancia, se dictó sentencia contra la empresa ferroviaria como responsable del accidente que ocasionó daños y perjuicios al accionante y se extendió la condena a la citada en garantía en la medida de la cobertura, declarando la oponibilidad al damnificado de la franquicia existente a cargo de la asegurada.

Por su parte, la Sala G de la Excma. Cámara Nacional en lo Civil admitió otros rubros indemnizatorios que habían sido reclamados, elevando el monto del resarcimiento a la suma de $\$ 1.238 .000$, con más los intereses y las costas del juicio. Asimismo, ratificó la extensión de la condena al asegurador y confirmó por mayoría la oponibilidad de la franquicia que había sido pactada en el importe de U\$S 125.000.

98 Cám. $4^{a}$ Apel. Civ., Com., Minas, Paz, Mendoza, 10/4/1973, "Carrión, C. G. por sí y su hijo menor c. I. Quiroga y otro", R.D.S., año 3, No 9, pág. 245.

99 CSJN, 18.11.2105, "Buján, Juan Pablo c/ Unidad de Gestión Operativa Ferroviaria de Emergencia LSM y ots. S/ Daños y perjuicios", DJ 09/03/2016, 21 con nota de Stigltiz, Rubén S.-Compiani, María F., RCyS 2016-VII, 177; RDCO 277, 340; Cita Online: AR/JUR/48696/2015. 
Dicha sentencia quedó firme y, por tanto, la empresa ferroviaria asegurada depositó en el expediente el importe de la franquicia, pretendiendo desligarse de la parte proporcional de los intereses y las costas del pleito.

La asegurada objetó la liquidación efectuada al efecto por la asegurada señalando que la franquicia (\$548.750 representativos de la suma de U\$S 125.000 al cambio vigente de la moneda nacional al momento del cumplimiento), significaba el 44,68\% de la condena, y reclamó que en la misma proporción la asegurada contribuyera la asegurada con relación a los intereses y costas condenados.

En primera instancia se hizo lugar al planteo de la aseguradora, mientras que, por su parte, la Sala interviniente, revocó el pronunciamiento en el entendimiento que como la condena superaba el monto de la franquicia no resultaba de aplicación tal débito de la asegurada en materia de intereses y costas. Puntualizó que, ello sólo tendría lugar en caso que el importe indemnizatorio fuera inferior al monto de la franquicia. A lo expuesto, añadió que las erogaciones en juicio debían ser cargadas por el asegurador en el entendimiento que constituían gastos de salvamento, en tanto tenían por objeto evitar o reducir el daño a cargo de la citada en garantía (art. 72 LS).

Para concluir, sostuvo que el asegurador no había alegado que la suma condenada superaba el límite de la garantía acordada, por lo que no resultaba de aplicación el art. $111 \mathrm{LS}$, y devenía improcedente tanto la actualización de la franquicia como el prorrateo de costas e intereses a cargo de la asegurada.

La aseguradora interpuso recurso extraordinario por arbitrariedad de la sentencia en la interpretación del art. 111 de la Ley 17.418 y, ante su rechazo, promovió la respectiva queja, la que fue atendida por el máximo Tribunal a pesar que la procuradora fiscal desaconsejara su tratamiento atento resultar una cuestión de interpretación de normas de derecho común, tarea propia del juez de la causa y ajena al remedio extraordinario (art. 14 Ley 48). Tampoco halló en la causa intereses generales de la sociedad que pudieran verse comprometidos y por cuya tutela debe velar el Ministerio Público Fiscal.

La Corte Suprema de Justicia de la Nación, en un pronunciamiento unánime, restableció la correcta interpretación del art. 111 de la Ley de Seguros. 
Para ello, destacó lo argumentado por la aseguradora: a) que no existía controversia en la causa sobre la existencia de la franquicia, su cuantía y su oponibilidad al damnificado; b) que sólo correspondía el pago íntegro por el asegurador (incluidas las costas e intereses) cuando se verifica el supuesto que se devengan por una decisión de prolongación innecesaria e injustificada de la causa por parte del asegurador, lo que no ocurrió en el caso, dado que la asegurada se defendió con sus propios abogados; c) que tanto la franquicia como la aplicación de la regla del prorrateo fueron invocados al contestar la citación en garantía y que la demandada asegurada guardó silencio respecto a su eventual aplicación; d) aun cuando las costas pudiera considerarse que revisten naturaleza salvamentista, igualmente el art. 73, segundo párr., establece la regla del prorrateo (por remisión a las reglas del infraseguro, art. 65, 2do. Párr. LS).

Por último, la citada en garantía precisó que la asegurada debe hacerse cargo de la franquicia independientemente del monto de la condena indemnizatoria y que cuando esta última es inferior a la cuantía de aquella, es el asegurado quien debe íntegramente el monto del capital condenado, así como de los intereses y costas del juicio.

La Corte Suprema de Justicia consideró que en el caso existía mérito suficiente para apartarse de su doctrina que veda el tratamiento de un asunto cuando remite a la interpretación del derecho común, por considerar que en el caso se había caído en una aseveración dogmática y carente de respaldo en la causa, al haber omitido dar a la controversia una solución adecuada de conformidad con la normativa vigente y las constancias comprobadas de la causa.

En primer lugar, caratuló con precisión que lo pactado resultaba ser una franquicia absoluta o incondicional lo que implica que el asegurado debe abonar dicha suma, en cualquier caso, con independencia del monto resultante de la condena.

En segundo lugar, añadió que la cuestión en debate quedaba reducida a la circunstancia de si la asegurada debía cargar o no proporcionalmente con intereses y costas, dado que había quedado consentido también lo abonado en concepto de franquicia. 
Para decidir el asunto, el máximo Tribunal señaló con estricta economía de fundamentos lo que la letra clara de la ley dispone “...Que si bien es cierto que la Ley 17.418 expresa que la finalidad del seguro de responsabilidad civil consiste en 'mantener indemne al asegurado por cuanto deba a un tercero en razón de la responsabilidad prevista en el contrato' (art. 109) y que 'la garantía del asegurador comprende los gastos y costas judiciales y extrajudiciales para resistir la pretensión del tercero' (art. 110, inc. a), también lo es que 'si el asegurado debe soportar una parte del daño, el asegurador reembolsará los gastos y costas en la misma proporción' (art. 111, segunda parte)'”.

Si no fuera ello suficientemente claro, la Corte añadió que aún en el caso de la asimilación de las costas a los gastos de salvamento, en el seguro contra la responsabilidad civil, ello no puede desconocer la manda expresa del art. 111, segunda parte LS, que resuelve expresamente la cuestión en orden a cargar al asegurado con la parte proporcional de los gastos y costas del pleito, cuando deba hacerse cargo de una parte de la condena.

Como consecuencia de ello, hizo lugar a la queja, dejó sin efecto la resolución apelada y ordenó dictar un nuevo pronunciamiento con arreglo a lo expresado.

\section{LOS LÍMITES EN EL SEGURO AUTOMOTOR OBLIGATORIO. LA CUESTIÓN EN EL MERCOSUR}

\section{a) E1 SOA en Argentina}

Como señalamos más arriba, el seguro contra la responsabilidad civil automotor fue implementado en Argentina, con carácter obligatorio ${ }^{100}$, a partir del 1 de febrero de 1993, mediante dec. 692/1992 (Adla LIIB-1725), que aprobó el Reglamento Nacional de Tránsito y Transporte. A partir de dicho momento conviven dos seguros de responsabilidad civil automotor: el tradicional seguro voluntario y el obligatorio creado a partir de la referida normativa.

100 En rigor, lo que consagró el art. 67 es una obligación: la de contratar un seguro "de acuerdo a las condiciones que fije la autoridad de control" y no un seguro obligatorio que constituya un sistema específico y diferenciado respecto del Código Civil, de Comercio y de la Ley de Seguros. 
El 23 de diciembre de 1994 se sancionó la Ley de Tránsito 24.449, publicada el 10 de febrero de 1995, cuyo artículo 68 reprodujo la obligación de contratar el seguro de responsabilidad civil automotor, delegando el diseño de su extensión en la autoridad de control de la actividad aseguradora. Con "ароуо" en la "delegación de facultades legislativas" otorgada por el dec. 692/1992, la Superintendencia de Seguros de la Nación, mediante la resolución 21.999 del 29 de diciembre de 1992 (Adla LIII-A-690), fijó las “condiciones" que debe reunir el seguro obligatorio. Al año siguiente, el 22 de enero de 1993, la Superintendencia de Seguros de la Nación dictó la res. 22.058, por la que se establecen «las condiciones mínimas de cobertura del seguro obligatorio al que deberán conformarse las entidades», dado que en los considerandos se señaló la conveniencia de uniformar "las condiciones contractuales" con el fin de favorecer una "fácil reproducción por parte de las aseguradoras".

Sobre la base de lo expuesto, el art. 1 de esta resolución establecía que "la cobertura mínima requerida... deberá otorgarse de conformidad con las condiciones y diagramación que se acompañan como Anexo I". Y éste contenía las condiciones generales uniformes a las que debían conformarse las entidades autorizadas para operar en el riesgo.

Estas resoluciones fueron abrogadas y, actualmente, se encuentra vigente la resolución SSN 39.927, que prevé en su Anexo I tanto las condiciones contractuales uniformes del seguro obligatorio de responsabilidad civil que exige la Ley de Tránsito como la del seguro voluntario de responsabilidad civil para automotores.

En el seguro obligatorio (SO-RC) se prevé un límite mínimo de $\$$ 400.000 para el caso de muerte o incapacidad total y permanente (cláusula 2 , inc. a, apart. 1) y en caso de pluralidad de damnificados en un mismo acontecimiento, del doble de dicha suma (a.3), así como de $\$ 30.000$ para gastos sanatoriales (b.1) y de $\$ 16.000$ por gastos de sepelio (1.2.1 y 1.2 .2 , respectivamente) ${ }^{101}$.

En cambio, en el seguro voluntario la última modificación que comenzó a regir a partir del 1 de setiembre de 2016 se fijan límites máximos

101 Equivalen respectivamente y en forma aproximada, a USD 26.500, USD 2.000 y USD 1.000. 
de cobertura de $\$ 6.000 .000$ para automóviles y motos, de $\$ 18.000 .000$ para taxis, remises, camiones, servicios de urgencias y de las fuerzas de seguridad y $\$ 30.000 .000$ para transporte.

Cabe afirmar que lo que ha consagrado la Ley de Tránsito es denominado como seguro obligatorio, pero él no ha sido regulado legislativamente, ya que en lo que debería constituir su contenido normativo, medió una remisión "a las condiciones que fije la autoridad en materia aseguradora".

Ello fue un error esencial y constituyó la génesis de la inconstitucionalidad del sistema, pues la Superintendencia de Seguros de la Nación, al "legislar", sobre contratos y responsabilidad civil, infringe lo dispuesto por el art. 75, inc. 12, de la Constitución Nacional, ya que se trata de temas reservados al Congreso de la Nación ${ }^{102}$.

Resulta claro que el sistema deja sin protección a las víctimas de los accidentes de tránsito, contraviniendo no sólo los principios de la Ley de Tránsito 24.449, sino también los que son comunes a la mayoría de regulaciones de seguro automotor obligatorio en el derecho comparado ${ }^{103}$.

En la hora actual, la tendencia universal exhibe el incremento de la implantación de seguros obligatorios contra la responsabilidad civil en aquellas actividades o supuestos de mayor incidencia en la producción de daños. Por otra parte, es claro que la obligación de contratar seguros no ha desplazado al seguro voluntario, sino que ambos se complementan, en tanto a través de estos últimos se cubren indemnizaciones o supuestos de responsabilidad no cubiertos por los obligatorios.

De esta manera, se posibilita que determinadas actividades potencialmente peligrosas o en la que los eventuales daños alcanzan una importante dimensión cuantitativa o cualitativa, frente a los que se origina una acusada sensibilidad social y para los que el principio "pro damnato" tiende a superar los límites de la responsabilidad civil tradicional, encuen-

102 Sobre la inconstitucionalidad de tal delegación, ver Stiglitz, Rubén S., "Inconstitucionalidad del régimen normativo que regula el seguro obligatorio automotor", LL del 14/10/2004, p. 1; "Responsabilidad civil. Doctrinas esenciales", t. III, p. 1649.

103 Piedecasas, Miguel A., Seguro obligatorio automotor, Rubinzal-Culzoni, Santa Fe, 2010, p. 175. 
tren una garantía de indemnidad para el asegurado y, primordialmente, la percepción de la indemnización por las víctimas.

La protección de las víctimas, en el caso de los accidentes de automotores, se convierte en la finalidad y justificación directa de la obligación de contratar un seguro de responsabilidad civil. Ahora bien, justamente en los sistemas del derecho comparado las exclusiones de cobertura se limitan a la mínima expresión. A modo de ejemplo, en la Unión Europea ha dictado una serie de directivas que constituyen un esquema moderno, completo y modelo a seguir en materia de seguro automotor obligatorio, en el cual la protección se extiende aun cuando el conductor no cuente con carnet habilitante, a los parientes del asegurado, etc. En algunos casos se impide directamente la oponibilidad de exclusiones de cobertura a terceros.

El art. 68, Ley de Tránsito sólo puede ser entendido como un dispositivo legal que obliga a contratar un seguro contra la responsabilidad civil automotor, pero no establece un régimen jurídico específico para estos seguros. En consecuencia, a ellos corresponde la aplicación del mismo régimen jurídico que al seguro voluntario (ley 17.418).

En otros términos, el establecimiento de una obligación legal de contratar un seguro no ha deslegalizado el régimen del seguro automotor obligatorio, desplazando de su aplicación a la Ley de Contrato de Seguro $^{104}$. Ello requeriría el establecimiento de un régimen singular que derogue, modifique o complemente al general de la ley 17.418 , lo que entre nosotros no ha acontecido, a pesar del reclamo de la doctrina ${ }^{105}$.

En este contexto, sin embargo, las conclusiones doctrinarias ${ }^{106} \mathrm{y}$ jurisprudenciales ${ }^{107}$ a las que pasamos revista más arriba, predican la

104 Bataller Grau, Juan; Latorre Chiner, Nuria y Olavarría Iglesia, Jesús, Derecho de los seguros privados, Marcial Pons, Madrid, 2007, p. 277.

105 Aguirre, Felipe F., "Seguro de responsabilidad civil. Los límites de la prestación a cargo del asegurador y el plenario 'Obarrio' (art. 118, ley 17.418)”, JA 2007-III-777.

106 Sobrino, Waldo A. R, "Las modificaciones a la ley de seguros por aplicación de la ley de defensa del consumidor”, RCyS 2011-II-37.

107 C. Nac. Civ., Sala L, 1/11/2011, "Álvarez, Rosa C. v. Expreso Gral. Sarmiento S.A s/daños y perjuicios", LL del 8/3/2012, p. 6, AR/JUR/92985/2011, en cuanto consideró que “...el art. 118, LS, no podría ofrecer resistencia válida. Esto es: el art. 118 , en tanto limitaría la ejecutabilidad de la sentencia 'en 
inaplicabilidad e incluso la inconstitucionalidad de la normativa de la Ley de Seguros que permite la oponibilidad de los límites de la cobertura, en orden a la existencia de un seguro obligatorio impuesto legalmente.

No compartimos tales conclusiones, que son fundadas en la normativa de orden público de defensa de los consumidores y usuarios. El loable esfuerzo de la protección de las víctimas no puede justificar constituir el juicio de daños como instrumento dañoso, consagrando una carga indemnizatoria que otro debería afrontar, o en mayor extensión que la procedente $^{108}$.

Sin embargo, esa tendencia que viene afirmándose revela la percepción como injusta de la solución que aplica al seguro automotor obligatorio a las exclusiones de cobertura que se justifican sólo en sede del seguro voluntario.

La solución no debe ser otra que el dictado de una ley de seguro obligatorio automotor que regule acabadamente la cuestión, que vede las tradicionales exclusiones de cobertura del seguro voluntario y que se convierta finalmente en un instrumento de protección de las cuantiosas víctimas de los accidentes de tránsito en nuestro país.

\section{b) La cuestión en el Mercosur}

Las pólizas argentinas de seguro automotor no acuerdan cobertura por los siniestros producidos o sufridos por el vehículo su carga en el mar territorial o fuera del territorio de la República Argentina.

la medida del seguro'no obstante la infracción de normas de orden público, es inaplicable al caso por inconstitucional. Esto así en tanto que, en la especie, supondría una cortapisa a la responsabilidad indistinta del asegurador que, integrado a una cadena o grupo productor de servicios riesgosos, ha ofrecido y concertado un seguro de responsabilidad civil a conciencia de que en los hechos deroga, a través de una mera disposición administrativa, normas de jerarquía superior y de orden público. O, como consideraran mis colegas de sala, Dres. Pérez Pardo y el recordado Rebaudi Basavilbaso, el art. 118, Ley de Seguro ha quedado implícitamente derogado para estos casos de aseguramiento obligatorio de la posterior ley 24.449. Sea por una u otra vía, no es aplicable al caso el art. 118 ".

108 Zavala de González, Matilde y González Zavala, Rodolfo M., "El juicio de daños como instrumento dañoso. Eximentes probadas de responsabilidad", RCyS, año XIV, nro. 3, marzo 2012, p. 151. Los autores señalan que “...Así el tribunal victimiza a uno de los litigantes, y crea judicialmente una obligación sin causa que justifique la condena o toda su extensión. Un perjuicio no se repara infiriendo otro a quien es ajeno a la situación nociva, o colocando en sus espaldas mayor peso indemnizatorio que el apropiado...". 
Sin perjuicio de ello, el asegurador y el asegurado pueden extender su cobertura, incluso la de responsabilidad civil, cuando el vehículo se encuentre circulando por un país extranjero.

Pero entre los países del Mercosur rige un acuerdo celebrado en la XV Reunión de Ministros de Obras Públicas y Transportes de los Países del Cono Sur-Acuerdo 1.41 (XV)- que autorizó la libre circulación de vehículos particulares y al transporte carretero, a condición que obtuvieren las siguientes coberturas.

Para daños a terceros no transportados:

a) Muerte y/o daños personales - USD 50.000 por persona (transporte carretero) y USD 40.000 por persona (automóviles particulares).

b) Daños materiales USD 30.000 por bien dañado (transporte carretero) y USD 20.000 (automóviles particulares).

En el caso de varias reclamaciones relacionadas con un mismo evento, la responsabilidad de la entidad aseguradora (tanto en el transporte carretero como en automóviles particulares) queda limitada a USD 200.000 por acontecimiento.

Para daños a pasajeros, la cobertura que sólo se brinda a empresas de transporte de personas:

a) Muerte y/o daños personales USD 50.000 por persona y USD 240.000 por acontecimiento.

b) Equipaje USD 1.000 por persona y USD 10.000 por acontecimiento.

No obstante, la determinación de los valores antes mencionados, el asegurado y la entidad aseguradora podrían acordar sumas aseguradas más elevadas, mediante cláusula particular.

Las coberturas acordadas en el tratado internacional limitan la protección por responsabilidad del conductor del vehículo por acontecimiento, en línea con los límites que rigen para los siniestros ocurridos dentro de nues- 
tras fronteras. Pero además limitan la garantía del asegurador a una suma máxima por damnificado, limitación que en las pólizas locales no existe.

Lo que es más importante, en el caso de vehículos particulares, la cobertura de la cláusula de MERCOSUR, sólo ampara la responsabilidad civil por daños a terceros no transportados, aunque el transporte benévolo sea de otras personas que no sean ascendientes, descendientes, colaterales o cónyuge, u otras que residan con él o que dependan del asegurado económicamente. Aclaremos que estos últimos tampoco están cubiertos en las pólizas locales.

Por este motivo podrían existir cuestionamientos a esta cláusula que, para un asegurado mal asesorado, sería sorpresiva.

Sin embargo, el art. 1121 del CCyCN prohíbe que se declaren abusivas las cláusulas que reflejan disposiciones vigentes en tratados internacionales o en normas legales imperativas. Nadie podría alegar sorpresa ante una disposición de rango legal, o aun supra legal (art. 75, inc. 12 $\mathrm{CN}$ ), ya que la fuente no sería contractual sino una norma que se presume conocida por todos.

A pesar de lo expuesto, hubo un precedente que, a juicio de los ponentes, constituye un inaceptable apartamiento de las normas que deben regir la cuestión. En el marco de un accidente de tránsito que tuvo lugar en la R.O. del Uruguay y en el cual se produjo la muerte de un pasajero transportado en forma benévola, los sucesores de aquel promovieron demanda contra el conductor del vehículo. Solicitaron la citación en garantía del asegurador, quien opuso la falta de cobertura invocando la Cláusula Mercosur.

Tanto en primera como en segunda instancia los jueces dieron la razón a los reclamantes y se extendió la condena a la citada en garantía. Interpuesto el recurso de queja ante la Corte Suprema de Justicia de la Nación, la misma lo desestimó por considerar que no había cuestiones que ameritaran la apertura de la vía extraordinaria. Sólo el voto en disidencia de la Ministra Highton de Nolasco acierta a señalar la transcendencia del tema en debate. En los sustancial, consideró que “...la disposición citada excluye de la cobertura de riesgos de la Póliza del Mercosur, a 
los daños que sufrieran las personas transportadas en el vehículo. Cabe tener presente que tales disposiciones no constituyen una limitación de responsabilidad, sino que importan una extensión de la cobertura contratada en el país, que opera de forma automática en las condiciones y con el alcance establecidos por el acuerdo internacional. Que el a quo prescindió de dicha normativa con solo apoyo en circunstancias fácticas $y$ de derecho común, lo que importa desconocimiento de los compromisos asumidos por el país en el ámbito del Mercosur, a la vez que coloca a las compañías aseguradoras de la República Argentina en desigualdad de condiciones respecto de las domiciliadas en otros estados parte, contraviniendo de tal modo los propios objetivos de las resoluciones adoptadas por el Grupo Mercado Común del Mercosur... "109.

\section{CONCLUSIONES}

Los límites económicos de la cobertura forman parte de la delimitación del riesgo asegurado y restringen el ámbito de la responsabilidad del asegurador.

La delimitación del riesgo asegurado se distingue de las cláusulas limitativas de los derechos de los asegurados: la delimitación del riesgo, comprensiva de las tareas de individualización y determinación de la base del riesgo asegurado, precede al nacimiento de los derechos y obligaciones de las partes y constituye el objeto del contrato.

En cambio, las cláusulas limitativas, tanto las exonerativas (que eliminan totalmente la responsabilidad), como las limitativas propiamente dichas (que la limitan parcialmente), evidencian el propósito de liberar o atenuar la responsabilidad del asegurador y, consecuentemente, del derecho de la víctima a obtener el pleno resarcimiento del daño.

En materia del seguro contra la responsabilidad civil, en Argentina, tanto la franquicia o descubierto obligatorio, como la suma asegurada, resultan oponibles al tercero en razón de integrar "la medida del seguro", y constituye el límite de la condena del asegurador (art. 118, LS).

109 CSJN, 04.09.12, Fernández, Liliana Mónica y ots. c/ Bonavera, Walter Oscar y ots. s/ daños y perjuicios", La Ley online, AR/JUR/52357/2012. 
El límite alcanza a la condena por capital. Si hubiere condena en exceso del límite o franquicia a cargo del asegurado, los intereses deberían calcularse proporcionalmente a la contribución de asegurado y asegurador en el pago del capital. Las costas causídicas deberán correr igual suerte. El asegurador deberá el pago de intereses y costas aunque superen el límite de la suma asegurada.

Estos principios rectores del seguro contra la responsabilidad civil, que hasta hace algún tiempo eran inconmovibles, comenzaron a ponerse en entredicho en numerosos fallos judiciales y en la doctrina,

Varios factores concurren a la aparición de estos cuestionamientos.

En primer lugar, en el mundo moderno, el principio de la autonomía de la voluntad en los contratos ha perdido su carácter absoluto, merced a la influencia de un orden público de protección.

También la sociedad ha cambiado su mirada sobre la responsabilidad civil. Ya no se trata de sancionar al responsable del daño, sino fundamentalmente de resarcir los daños sufridos por las víctimas, lo que ha acentuado la aparición de seguros obligatorios donde límites y franquicias no dejan de cuestionarse cuando obstan a esa finalidad.

A ello podemos añadir que la protección del asegurador siempre fue concebida como una obligación dineraria. El fenómeno inflacionario lesiona gravemente los límites de la cobertura, y la depreciación es aún más acentuada en coberturas de "cola larga", como ciertamente son los seguros contra la responsabilidad civil.

Finalmente, pero no menos importante, es la aparición de la protección al consumidor en las Constituciones y Leyes de los países libres. Como consecuencia, hay una mirada crítica a prácticas tales como la imposición de sumas aseguradas irrisorias o franquicias exageradas por parte de los aseguradores. De esta manera, los propios asegurados, en ocasiones, se suman a quienes cuestionan los límites al seguro contra la responsabilidad civil. 


\section{BIBLIOGRAFÍA}

Aguirre, Felipe F., "Seguro de responsabilidad civil. Los límites de la prestación a cargo del asegurador y el plenario 'Obarrio' (art. 118, ley 17.418)”, JA 2007-III-777.

Alterini, Atilio A., “Contratos. Civiles-Comerciales-de consumo. Teoría General”, Ed. Abeledo Perrot, Buenos Aires, 1998.

Alterini, Atilio A., "Moratoria para los autotransportistas", LL 1997-B, 1295 y "Limitación de la responsabilidad ¿sólo para los autotransportistas?, LL 1997-E, 1333.

Barbato, Nicolás H., "Exclusiones a la cobertura en el contrato de seguros”, ED 136-547.

Bataller Grau, Juan; Latorre Chiner, Nuria y Olavarría Iglesia, Jesús, Derecho de los seguros privados, Marcial Pons, Madrid, 2007.

Bidart Campos, Germán, Manual de la Constitución reformada, t. 3, Ed. Ediar, Bs. As., 2001.

Castro Sanmartino, Mario. E.-Schiavo, Carlos A., Seguros, LexisNexis, Buenos Aires, 2007.

Compiani, M. Fabiana, "La irrazonabilidad de la cuantía de la franquicia", LL del 12 de diciembre de 2006.

Diez-Picazo y Ponce de León, Luis, (Ponente General) Las condiciones generales de la contratación y cláusulas abusivas, Civitas, Madrid, 1996.

Donati, Antígono, Trattato del dirittodell'assicurazioniprivate, v. III, Milano 1956.

Gregorini Clusellas, Eduardo L., "La obligación de seguridad hacia el pasajero y la franquicia del seguro", LL 2006-LA LEY 11/12/2006.

Halperin, Isaac, Seguro, $3^{\mathrm{a}}$ ed. actual. y ampl. por Barbato, Nicolás H., Depalma, Buenos Aires.

López Saavedra, Domingo M., Ley de Seguros Comentada y Anotada, La Ley, Bs. As., 2007.

López Saavedra, Domingo M. en Martorell, Eduardo (Director), Tratado de Derecho Comercial (Tomo V-Seguros). Ed. La Ley 2010.

Lorenzetti, Ricardo L., Consumidores, 2a ed. Act., Rubinzal Culzoni, Santa Fe, 2009.

Meilij, Gustavo R., Manual de Seguros, Depalma, Buenos Aires, 1994.

Meilij, Gustavo Raúl, Franquicia y descubierto obligatorio, RCyS 2012-VII, 207. 
Morandi, Juan C. F. "Estudios de Derecho de Seguros". $1^{\circ}$ Ed. Pannedille. Buenos Aires, 1971.

Picard, M. - Besson, A., Les Assurances terrestres”, LGDJ, Paris, 1982, T. I.

Piedecasas, Miguel A., Seguro obligatorio automotor, Rubinzal-Culzoni, Santa Fe, 2010.

Sánchez, Diego C., "Franquicias y descubiertos", en la obra colectiva patrocinada por la Academia Judicial Internacional, DUPUIS, Juan Carlos (Coord.), Seguros I, La Ley, Bs. As., 2008.

Sánchez Calero, Fernando, "Seguro de Responsabilidad Civil”, en Sánchez Calero, Fernando (Director) Ley de Contrato de Seguro. Comentarios a la Ley 50/1980 de 8 de octubre y a sus modificaciones. Thomson-Aranzadi, $3^{\circ}$ edición, Navarra, 2005.

Signorino Barbat, Andrea, Los seguros de responsabilidad civil, Fundación de Cultura Universitaria, Montevideo, 2011.

Sobrino, Waldo A. R, "Las modificaciones a la ley de seguros por aplicación de la ley de defensa del consumidor", RCyS 2011-II-37.

Stiglitz, Rubén S., “Teoría y Práctica del Derecho de Seguros”, Ed. La Ley, Buenos Aires.

Stiglitz, Rubén S., "Contratos Civiles y Comerciales. Parte General”, t. I, Ed. AbeledoPerrot, Buenos Aires, 1998.

Stiglitz, Rubén S., Derecho de seguros, $6^{\text {a }}$ ed. act. y ampl., t. 1/5, La Ley, Buenos Aires, 2016.

Stiglitz, Rubén S., “La franquicia y su oponibilidad a terceros”, RCyS, 2004-72.

Stiglitz, Rubén S., "Inconstitucionalidad del régimen normativo que regula el seguro obligatorio automotor", LL del 14/10/2004, p. 1; "Responsabilidad civil. Doctrinas esenciales", t. III, p. 1649.

Stiglitz, Rubén S., "La franquicia en el autotransporte público de pasajeros en el pensamiento de la Corte", JA del 17 de octubre de 2007.

Stiglitz, Rubén S. y Stiglitz, Gabriel A. Derecho de Seguros. $5^{\circ}$ edición actualizada y ampliada. Buenos Aires, La Ley, 2008. Tomo IV.

Stiglitz, Rubén S. y Compiani, María Fabiana “La viabilidad de la declaración de oficio de la inconstitucionalidad de la franquicia en el seguro de transporte automotor de pasajeros" y en Responsabilidad Civil y Seguros 2006-VI. 
Stiglitz, Rubén S.-Compiani, María F., "El orden público en el contrato de seguro", LA LEY 2015-F, 622.

Tolosa, Pamela, "El seguro obligatorio y la franquicia en un contexto de insolvencia: ¿nuevas soluciones en la ley de defensa del consumidor?, RCyS, 2010-II, 139.

Traverso, Amadeo E., "La medida del seguro en la cobertura del riesgo de responsabilidad civil automotor y "La canción del pirata”, el Dial DC21E7, 22/09/2016.

Vázquez Ferreyra, Roberto A., "El seguro de responsabilidad civil y las cláusulas claimsmade", LA LEY 2006-E,8 • Derecho Comercial Doctrinas Esenciales Tomo IV, 491. Cita Online: AR/DOC/2696/2006.

Veiga Copo, Abel B., Tratado del Contrato de Seguro, 2a ed., Civitas-Thomson Reuters, España 2012.

Veiga Copo, Abel B., Los principios de derecho europeo del contrato de seguro, Pontificia Universidad Javeriana-CEDEP-Grupo Editorial Ibañez, Colección Prospectivas del Derecho nº 2, Bogotá, 2012.

Zavala de González, Matilde y González Zavala, Rodolfo M., "El juicio de daños como instrumento dañoso. Eximentes probadas de responsabilidad", RCyS, año XIV, nro. 3, marzo 2012. 